Review

\title{
Current Status of Single Particle Imaging with X-ray Lasers
}

\author{
Zhibin Sun $1,2,3$, Jiadong Fan ${ }^{3}$, Haoyuan $\mathrm{Li}^{2,4}$ and Huaidong Jiang ${ }^{3, *}$ \\ 1 State Key Laboratory of Crystal Materials, Shandong University, Jinan 250100, China; \\ zbsun@slac.stanford.edu \\ 2 Linac Coherent Light Source, SLAC National Accelerator Laboratory, Menlo Park, CA 94025, USA; \\ haoyuan@slac.stanford.edu \\ 3 School of Physical Science and Technology, ShanghaiTech University, Shanghai 201210, China; \\ fanjd@shanghaitech.edu.cn \\ 4 Department of Physics, Stanford University, Stanford, CA 94305, USA \\ * Correspondence: jianghd@shanghaitech.edu.cn
}

Received: 20 December 2017; Accepted: 10 January 2018; Published: 22 January 2018

\begin{abstract}
The advent of ultrafast X-ray free-electron lasers (XFELs) opens the tantalizing possibility of the atomic-resolution imaging of reproducible objects such as viruses, nanoparticles, single molecules, clusters, and perhaps biological cells, achieving a resolution for single particle imaging better than a few tens of nanometers. Improving upon this is a significant challenge which has been the focus of a global single particle imaging (SPI) initiative launched in December 2014 at the Linac Coherent Light Source (LCLS), SLAC National Accelerator Laboratory, USA. A roadmap was outlined, and significant multi-disciplinary effort has since been devoted to work on the technical challenges of SPI such as radiation damage, beam characterization, beamline instrumentation and optics, sample preparation and delivery and algorithm development at multiple institutions involved in the SPI initiative. Currently, the SPI initiative has achieved 3D imaging of rice dwarf virus (RDV) and coliphage PR772 viruses at $\sim 10 \mathrm{~nm}$ resolution by using soft X-ray FEL pulses at the Atomic Molecular and Optical (AMO) instrument of LCLS. Meanwhile, diffraction patterns with signal above noise up to the corner of the detector with a resolution of $\sim 6 \AA \AA$ Angström $(\AA)$ were also recorded with hard $X$-rays at the Coherent X-ray Imaging (CXI) instrument, also at LCLS. Achieving atomic resolution is truly a grand challenge and there is still a long way to go in light of recent developments in electron microscopy. However, the potential for studying dynamics at physiological conditions and capturing ultrafast biological, chemical and physical processes represents a tremendous potential application, attracting continued interest in pursuing further method development. In this paper, we give a brief introduction of SPI developments and look ahead to further method development.
\end{abstract}

Keywords: X-ray free-electron lasers; XFEL; coherent diffraction imaging; single particle imaging; resolution

\section{Coherent Diffraction Imaging Using Synchrotron Light Source}

High-resolution structure determination of macromolecular and biological particles is an important tool for the life science and biological community [1-4]. Apart from X-ray crystallography and spectroscopy, microscopy is the most widely used technique for structure determination in physical, material and biological sciences. Multiple imaging methods, such as optical microscopy (including general optical microscopy, laser confocal microscopy and super-resolution microscopy) [5-9], electron microscopy [10-13] and X-ray microscopy [14-16] have been employed by researchers. Nevertheless, the resolution of an optical microscope is always limited by the wavelength of the radiation used ( $200 \mathrm{~nm}$ for visible light). For super-resolution microscopy, the sample has to be labeled, which will 
limit the applications of photoactivated localization microscopy (PALM) [17], stochastic optical reconstruction microscopy (STROM) [18] and stimulated emission depletion (STED) [19]. For scanning electron microscopy (SEM), it can only provide surface information [20]. Regarding transmission electron microscopy (TEM) [21], the penetration ability of electrons is a critical issue. The sample thickness has to be less than $50 \mathrm{~nm}$ [22], otherwise contrast is reduced due to multiple scattering of the electrons. To obtain structural information below the surface for thick samples, the sample has to be sliced, introducing artifacts in the final images. Compared to electrons, $\mathrm{X}$-rays have a larger penetration depth, making them an ideal probe for most applications in structure determination. However, the scattering cross-section of X-rays is smaller than that of electrons [23]. The scattering efficiency is worse than that of electrons. Actually, neither X-rays nor electrons can achieve atomic resolution due to the limitation of radiation damage [24]. Only when the X-ray or electron pulse is shorter than the atomic motion timescale, such as in the order of $10 \mathrm{fs}$, could the valid snapshot be captured [25]. Under the same conditions, $\mathrm{X}$-rays are better for thick samples without slicing and electrons are better for weak scattering samples with cryogenic cooling. Classical X-ray imaging methods, such as transmission X-ray microscopy (TXM), scanning transmission X-ray microscopy (STXM) and X-ray fluorescence imaging are based on X-ray optics [26] which will limit the highest obtainable resolution. At the moment, the achievable resolution of focusing optics has broken the $10 \mathrm{~nm}$ barrier [27,28]. For X-ray crystallography, the samples have to be crystallized typically to a certain minimum size to obtain high resolution [29]. In addition to crystal growth and phasing, radiation damage is an extra challenge, especially when radiation sensitive samples such membrane or metal containing proteins.

In 1952, D. Sayre underlined in a half-page paper that by measuring the diffraction intensity between the Bragg peaks, the phase problem of non-crystalline samples might be resolved [30]. Since then, oversampling theory [31,32] and different types of phase retrieval algorithms [33-41] have developed rapidly. In 1999, J. Miao and colleagues performed the first successful coherent diffraction imaging experiment [42]. This newly developed coherent diffraction imaging method is a form of lensless microscopy rather than relying on X-ray optics. The theoretical resolution is only limited by the incident light wavelength and the maximum diffraction angle recorded by the detector. The past 18 years have witnessed a great success of coherent diffraction imaging, especially under the use of high flux X-ray light source facilities, such as advanced 3rd generation synchrotron facility Super Photon ring-8 GeV (Spring-8, Hyogo, Japan), European Synchrotron Radiation Facility (ESRF, Grenoble, France) and Advanced Photon Source (APS, Lemont, IL, USA). With developing X-ray instrumentation and phase retrieval algorithms, coherent $\mathrm{X}$-ray diffraction microscopy has been extended to nanoparticles [43-48], mineral materials [49,50], biological cells, bacteria and viruses [51-63]. Meanwhile, different CDI methods also developed quickly, such as Bragg-CDI [43,44,46,48], Fresnel-CDI [64], Keyhole-CDI [65], Reflective-CDI [66] and Ptychography [67,68]. These methods greatly increased the diversity and breadth of applications. Some technologies were incorporated from Cyro-EM, for example, Cryo-CDI [55,56] and wet-CDI [60]. These borrowed technologies make high-resolution imaging without obvious radiation damage possible.

In order to summarize the areas of attention for coherent X-ray diffraction microscopy, $\sim 200$ published papers were analyzed. Fifty of them $[24,31,32,38,42-87]$ were selected to generate the word cloud of Figure 1 which shows that reconstruction, diffraction, sample, resolution, structure and coherent are the most used terms during the last 18 years of synchrotron-based CDI papers. Besides, exposure, photons and radiation are also frequently used words. These suggest that published efforts have focused intensely on phase retrieval. It seems the reconstructed real space image was the main aspect of a publication a decade ago. Furthermore, the type of samples and the achieved resolution are also some of the most important parts of the selected papers. For biological specimen, radiation damage has also been a concern. From M. Howells's summarizing information [24], it can be found that one should be able to image a frozen-hydrated biological sample with CDI at a $10 \mathrm{~nm}$ resolution. To our knowledge, the currently published results showed that the best 3D image of biological samples' 
resolution is $\sim 30 \mathrm{~nm}$ [61], which is a little far away from the $10 \mathrm{~nm}$ resolution under the maximum radiation dose tolerance using a third-generation synchrotron light source. This lags behind the atomic resolution achieved by electron microscopy. For the similar samples, such as human chromosome, the resolution of 3D structures with CDI and Cryo-EM is $\sim 120 \mathrm{~nm}$ [57] and $\sim 50 \mathrm{~nm}$ [88], respectively.

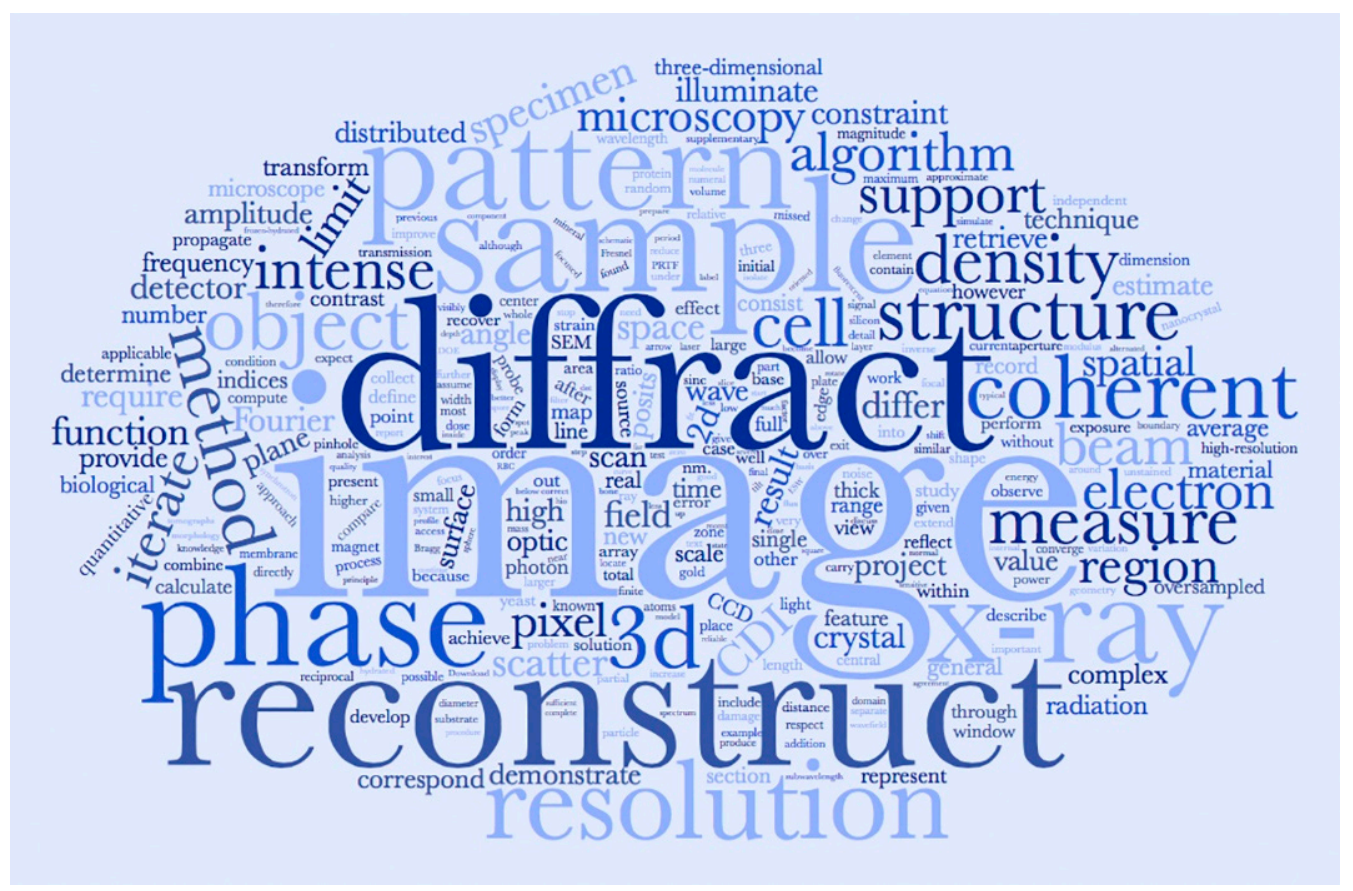

Figure 1. Word cloud of synchrotron-based coherent diffraction imaging published research papers. About 50 widely-read published papers were downloaded. These papers are published during the last 18 years since the first coherent diffraction imaging experiment was conducted successfully in 1999. The main text of the papers was analyzed by open python codes. The frequency of each meaningful word was calculated and then demonstrated by different size and colors. The bigger the size means the larger the frequency. The image shows that reconstruction, sample, phase and resolution are the most used terms for the past 18 years of coherent diffraction imaging research. At the same time, structure, intensity and radiation have also been key topics for biological imaging since 1999. (Original datas were collected from References [24,31,32,38,42-87]. Figure was generated under the help of Github open codes [89].).

The advent of a fourth-generation source, diffraction-limit storage ring (DLSR), opens a promising pathway for CDI [90-92]. The low transverse emittance and beam divergence improve the coherent fraction of the X-ray beam, especially for hard X-rays. The direct result is that the coherent photon of DLSR will be higher than that of current synchrotron light source. The obtainable resolution for CDI scales directly with the spatial coherence (as long as damage can be avoided). At the moment, many facilities around the world intend to update or build DLSR facilities [93], such as ESRF Upgrade Phase II [94], Spring-8 [95], MAX-IV [96], Sirius [97], etc. Looking forward, the investment X-ray facilities are putting into DLSR operations will yield new science possibilities for CDI.

\section{Coherent Diffraction Imaging with X-ray Lasers}

During the rapid development of CDI, the X-ray light source technologies have also made great progress. Thanks to the advent of ultra-intense and ultrafast X-ray free-electron lasers [98,99], the femtosecond pulses can outrun main radiation damage processes [100] using the so-called "diffraction-before-destruction" strategy [101]. Under proper conditions, XFELs can limit radiation damage and provide clear images of molecules that can otherwise be damaged using a continuous 
illumination. The state-of-the-art serial femtosecond crystallography (SFX) [102] and single particle imaging (SPI) methods [103] have proven to be promising ideas for native structure determination, with the additional benefit of time-resolution for making movies of reactions. Due to noise, detector limitation and demand of large amount dataset for atomic resolution, big data and automatic data analysis are needed to achieve the challenging goal.

Owing to the ultra-intense and ultrafast X-ray pulses generated by FLASH (Hamburg, Germany) [104,105], LCLS (Menlo Park, CA, USA) [106,107], SACLA (Hyogo, Japan) [108,109] and FERMI (Trieste, Italy) [110,111], many exciting CDI results have been obtained. It is worthwhile mentioning that the European-XFEL [112] and PAL-XFEL [113] have recently been commissioned, and that Swiss-FEL [114] is under construction and soon to be commissioned. The Shanghai Soft XFEL $[115,116]$ is under construction, and a hard XFEL facility has also been proposed [117]. We believe that the newly-built facilities will continue to be a great impetus to ultra-small and ultrafast research.

Coherent diffractive imaging experiments with X-ray free-electron lasers (XFEL-CDI) have studied a wide range of samples including man-made objects, nano-materials, clusters, and aerosol particles in the gas phase [101,118-132]. Many of these were used to test the validity of XFEL-CDI and included measurements of the morphology of complex structures, functional imaging method development, and dynamic changes under a stimulus (pump-probe). On the biological side, viruses, bacteria, organelles and associated biological components have been imaged at various resolution levels [133-142] and have helped further develop high throughput imaging methods.

Figure 2 shows typical results from non-biological particles using XFEL-CDI. The first experiment demonstrating the "diffraction-before-destruction" principle using the FLASH soft X-ray free-electron laser by H. Chapman and colleagues [101] is shown on Figure 2a. An intense pulse with $10^{12}$ photons at $32 \mathrm{~nm}$ wavelength was transported to a nanostructured non-periodic object. A speckled pattern was obtained before the beam completely destroyed the nanostructure. The diffraction pattern and the reconstructed real-space image showed no measurable effect from radiation damage. The final imaging resolution was estimated to be $62 \mathrm{~nm}$, where the phase retrieval transfer function (PRTF) drops to a value of $1 / \mathrm{e}$. After this successful demonstration of the principle, pump-probe methodologies were applied to XFEL-CDI. Figure $2 b, c[120,128]$ show time-resolved imaging of transforming materials under a visible light stimulus at FLASH and LCLS, respectively. Dynamic changes in man-made structures (Figure 2b) and nanoparticles (Figure 2c) were observed. Such measurements represent examples of the truly unique power of XFELs to study dynamic systems.

Other methods can also be combined with XFEL-CDI to yield further information. Figure 2d [126] shows the functional imaging of multiple nanoparticles. Time-of-flight mass spectrometry was used simultaneously with imaging, which allowed the morphology and chemical content to be captured at the same time by a single shot. Other methods such as fluorescence and emission spectroscopies can also be applied to reveal specific chemical information and correlate it to the structure revealed by imaging.

Three-dimensional imaging is typically not only desired but also necessary to fully understand a system being studied. However, focused XFEL pulses are too intense and destroy the sample typically in one pulse, limiting the information available to two-dimensions in one pulse. Without attenuation, the ultra-intense pulses will destroy almost all particles interacting with the X-ray laser [143]. Three-dimensional images typically cannot be obtained by rotating samples using an X-ray FEL which makes computed tomography (CT) and transmission X-ray microscopy (TXM) regularly performed at synchrotron light sources not particularly suitable for XFELs. Three-dimensional information is obtained using an XFEL by using re-producible particles delivered to the X-ray laser pulses one at a time. In this manner, thousands to hundreds of thousands of diffraction patterns with random orientations are recorded by large pixel array detectors. Using methods such as diffusion maps or threshold methods, valid hits and single-particle hits can be selected and their relative orientation can be determined. After phase retrieval, high-resolution real-space images can be obtained. 
Worthy of noted, J. Miao and colleagues developed a single-shot 3D imaging method for high-symmetry objects and demonstrated the idea on gold nanoparticles with X-ray lasers [131]. Figure 2e shows a 3D image of a nanoparticle from SACLA. By using the symmetry of gold nanoparticles, 48 diffraction patterns were generated. The 3D image was obtained after the finding of common arcs and phase retrieval. The final resolution was determined to be $\sim 5.5 \mathrm{~nm}$.
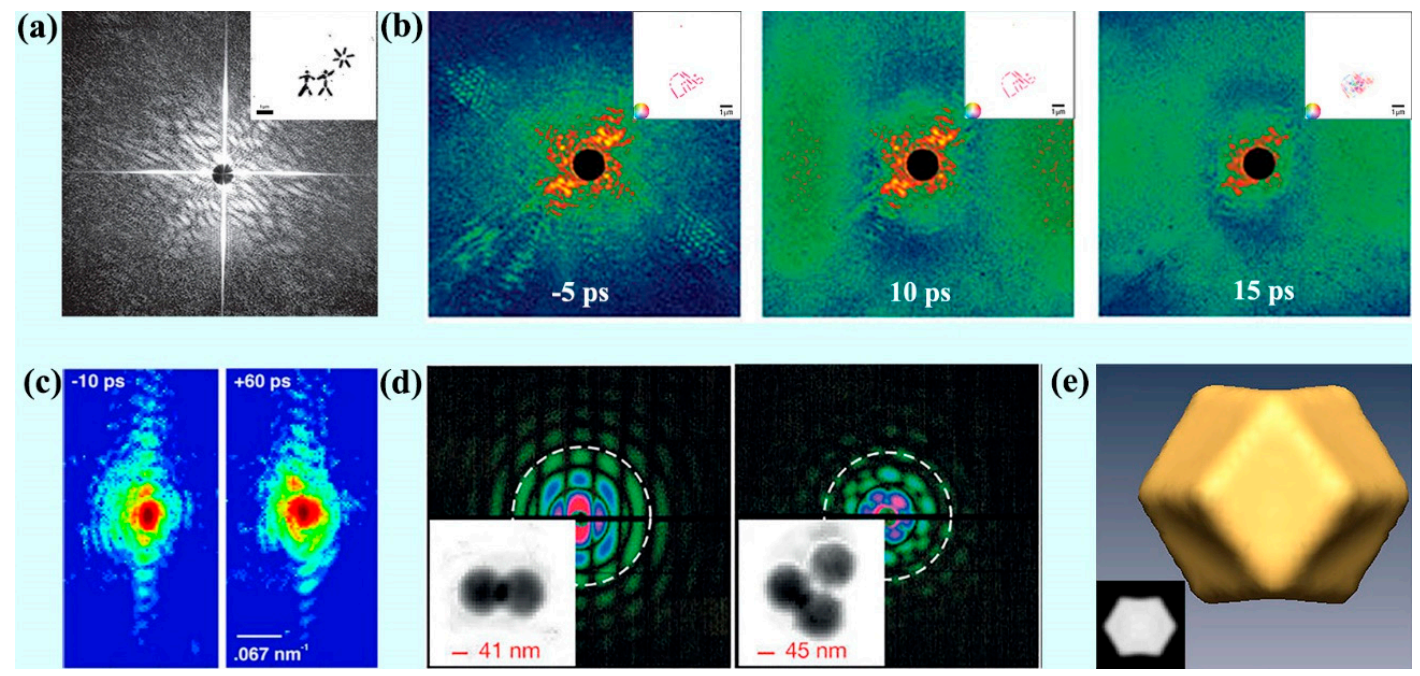

Figure 2. Coherent diffraction imaging of materials with or without pump-probe using X-ray free-electron lasers. (a) The first demonstration of coherent diffraction imaging with X-ray lasers at FLASH in 2006. The concept of "diffraction-before-destruction" was demonstrated at the limited resolution available; (b) Time-resolved diffractive imaging of a man-made sample. Laser-pump $\mathrm{X}$-ray-probe was applied at different time delays. In this case, the sample is seen to get destroyed under the high pump laser intensity and the features are disappearing after 15 ps; (c) Bragg coherent diffraction imaging of gold nanoparticles with hard X-ray lasers was employed at the Linac Coherent Light Source (LCLS). For different time delays, the changes in the diffraction patterns can be used to image phonon dynamics; (d) Morphology and chemical components of aerosol particles were captured by coherent diffraction imaging combined with time-of-flight mass spectrometry at LCLS; (e) Three-dimensional imaging of nanoparticle from SACLA. By using the symmetry of gold nanoparticles, 48 diffraction patterns were generated. The 3D image was obtained after the finding of common arcs and phase retrieval. The resolution as determined by Fourier shell correlation (FSC) is $\sim 5.5 \mathrm{~nm}$. (Figure $2 \mathrm{a}$ was reproduced with permission from [101]. Copyright Springer Nature, 2006. Figure $2 b$ was reproduced with permission from [120]. Copyright Springer Nature, 2008. Figure 2c was reproduced with permission from [128]. Copyright The American Association for the Advancement of Science, 2013. Figure 2d was reproduced with permission from [126]. Copyright Springer Nature, 2012. Figure 2e was reproduced with permission from [131]. Copyright Springer Nature, 2014.).

Compared to non-bioparticles, the coherent scattering cross-section of bioparticles is typically much smaller as they are composed of low atomic number elements primarily carbon, oxygen, nitrogen and hydrogen. In other words, the scattering signal of bioparticles is less than other particles when the particle size and photon parameters are the same. For example, the coherent scattering cross-section of gold $\left(19.32 \mathrm{~g} / \mathrm{cm}^{3}\right)$ and DNA $\left(\mathrm{C}_{10} \mathrm{H}_{11} \mathrm{~N}_{4} \mathrm{O}_{6} \mathrm{P}, 1.70 \mathrm{~g} / \mathrm{cm}^{3}\right)$ are $6.5 \mathrm{~cm}^{2} / \mathrm{g}$ and $0.4 \mathrm{~cm}^{2} / \mathrm{g}$ under $7 \mathrm{keV}$. However, the scattering ability of gold is over 100 times stronger than that of DNA. The weak scattering and low signal-to-noise-ratio (SNR) make high-resolution imaging of biological samples more challenging. Figure 3a [135] shows the first coherent diffraction imaging of biological samples at LCLS. High-quality diffraction data were obtained with a single X-ray laser pulse from a mimivirus. The reconstructed exit wavefront (image) shows a full-period resolution of $32 \mathrm{~nm}$. Single cell, virus or bacteria imaging is of potential great importance to disease detection and drug design. It enables the 
collections of separate cell images from individual cells and high-throughput imaging over populations of cells can sample unique occurrences. In this big data era, images from populations of genetically identical cells often reveal heterogeneous phenotypes, which can be helpful to group behavior research. Figure $3 \mathrm{~b}$ [137] shows the high-throughput imaging of heterogeneous cell organelles with $120 \mathrm{~Hz}$ X-ray laser pulses from LCLS. Morphology and inner electron density were reconstructed by phase retrieval automatically. This result could pave the way for further biological functional imaging with XFEL. Figure $3 c$ [136] demonstrates the combination of synchrotron XFEL together for one sample where one facility could not solve all challenges. This combined experiment illustrates the differences between facilities. Figure 3d [141] shows the successful demonstration of living cell imaging of cyanobacteria. Living cyanobacteria were injected into the $\mathrm{X}$-ray beam using an aerosol injector. During the short delivery time from solution to the vacuum of the experimental chamber, the cyanobacteria remain in a living state and they were then imaged by coherent diffraction. This demonstrates the capability for the real structure determination of biological samples under near native state. Figure 3e shows the first 3D imaging of biological samples using an XFEL [139]. Hundreds of diffraction patterns with different SNR and random orientations were recorded. After hit finding, pattern classifications, orientation determination and phasing, a 3D real-space volume with a full-period resolution of $120 \mathrm{~nm}$ was generated. This demonstration paves the way for 3D single-particle imaging, with the ultimate goal of achieving atomic resolution requiring further effort.
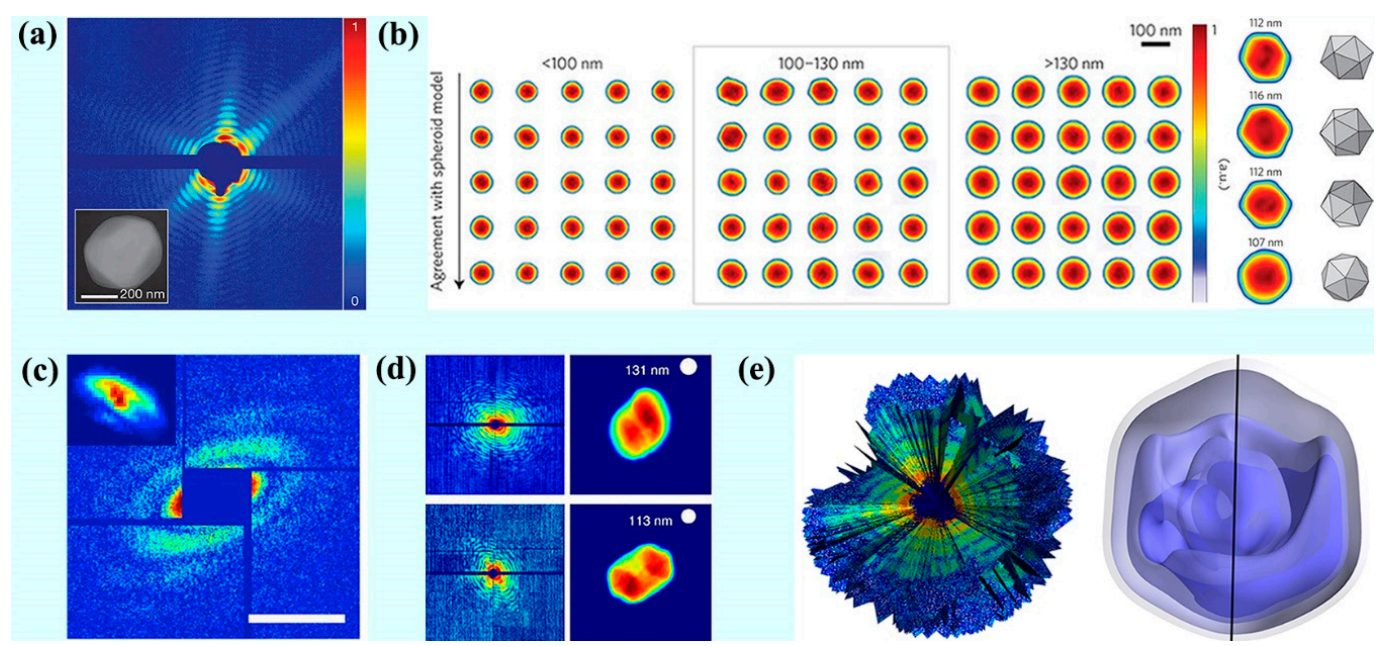

(e)
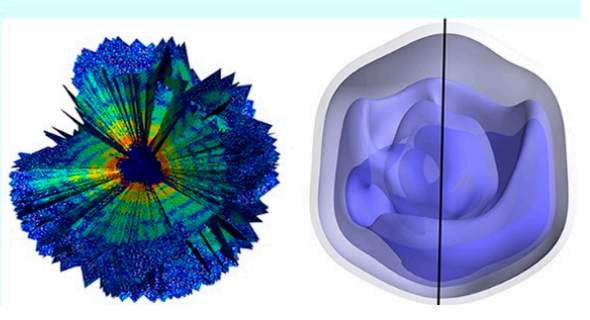

Figure 3. Coherent diffractive imaging of biological samples with $X$-ray free-electron lasers. (a) First coherent diffraction imaging of biological samples with hard X-ray lasers at LCLS. The sample, mimivirus, is one of the largest known viruses. The total diameter of the particle, including fibrils, is about $750 \mathrm{~nm}$. The full-period resolution of this first demonstration is $\sim 32 \mathrm{~nm}$; (b) High-throughput imaging of heterogeneous cell organelles. Around 70,000 low-noise diffraction patterns were collected within $12 \mathrm{~min}$ at LCLS at a frequency of $120 \mathrm{~Hz}$. Real space images with different organelles' size and shape were phased automatically; (c) Structure determination of RNAi microsponge combining single-shot X-ray free-electron laser (XFEL) diffraction with synchrotron-based coherent diffraction imaging; (d) Living cell imaging of cyanobacteria with XFEL. Living cyanobacteria were injected to the X-ray laser using an aerosol particle injector; (e) The first demonstration of three-dimensional imaging of biological samples. Mimivirus was delivered to the $\mathrm{X}$-ray laser beam, hundreds of random orientation diffraction patterns were collected. After hit finding, single-shot classification and orientation determination, a three-dimensional diffraction volume was obtained. The spatial resolution was estimated to $\sim 125 \mathrm{~nm}$. (Figure 3a was reproduced with permission from [135]. Copyright Springer Nature, 2011. Figure 3b was reproduced with permission from [137]. Copyright Springer Nature, 2014. Figure 3c was reproduced with permission from [136]. Copyright Springer Nature, 2014. Figure 3d was reproduced with permission from [141]. Copyright Springer Nature, 2015. Figure 3e was reproduced with permission from [139]. Copyright American Physical Society, 2015). 


\section{Single-Particle Imaging with X-ray Lasers}

As mentioned above, coherent diffraction imaging with $\mathrm{X}$-ray lasers has undergone a fast development and many high-profile results have been achieved. However, the published resolution has been limited, and there is a huge gap between the current resolution and atomic-scale resolution. In order to deeply investigate the limitations and move forward, start-to-end considerations have to be taken. The light source, such as the photon energy, pulse duration and pulse energy need to be optimized. X-ray instruments, such as optics, focusing mirrors, front-end slits and apertures before the sample, also need to be optimized for the measurement. Sample delivery systems, such as aerosol injectors, liquid-jet injectors and fixed targets, need development, optimization and suitable design for different experiments. Data acquisition system, such as high quantum efficiency (QE) and high dynamic range detectors, online data monitoring and analysis software, phase retrieval algorithms, will greatly affect the efficiency and validity of final images.

To speed up the progress and take full advantage of the scientific community around the world, LCLS launched an international cooperation team in December 2014, the Single-Particle Imaging initiative, which includes more than 100 scientists from 21 institutions over eight countries. A step-by-step roadmap was published where a host of challenges was outlined to guide the required developments. A series of experiments has been dedicated to systematically address the challenges of SPI.

\subsection{The Road Map}

To achieve atomic-scale resolution, such as $3 \AA$, the SPI initiative analyzed all the factors that could limit the resolution from the start to the end of the experiment. To initiate this work, workshops and brainstorming sessions were arranged to clarify the steps to undertake. Following the published roadmap [103], the following key challenges were identified:

(1) Radiation damage;

(2) Start-to-end simulation pipeline;

(3) Samples issues;

(4) Sample delivery system;

(5) Characterization of parasitic scattering and noise;

(6) Beam diagnostics and characterization;

(7) Data analysis and phase retrieval algorithms development.

\subsection{Setup and the Experiment Procedure}

Many aspects are required to be specified prior to conducting an SPI experiment. First, the proposed resolution, sample type and size should be defined. Special diagnostics required for the experiment, such as the ion/ $\mathrm{e}^{-}$TOF, high speed camera, fluorescence detector and pumping laser system and the space they require should also be taken into consideration. Secondly, the ideal sample-to-detector-distance, photon energy, pulse duration, and pulse energy should be determined. Then, careful alignment of all optics, slits, KB mirrors and large-panel pixel array detectors must carefully be accomplished at the start of the beamtime. Simultaneously, beam characterization, such as the beam profile, the focused beam spot size, beam intensity and position fluctuations, wavefront or arrival time should be diagnosed for further reference. The high harmonic content of the beam should also ideally be tested. Finally, selection of a proper sample delivery method will be of great importance to the background and hit rate. The simple flow chart of the experiment and data process is shown in Figure 4. After alignment of the instrumentation, samples are delivered into the X-ray laser beam path. The forward scattering exit wavefront will propagate downstream and then to be recorded by the detector and this pattern must be oversampled properly. Data processing involves center determination, background subtraction, analog-to-digital units (ADU) to photons conversion, hit finding, pattern classification, and orientation 
determination. Finally, phasing can produce a real-space 3D image. By using PRTF, FSC or other criteria, the spatial resolution could be determined.

\subsection{Current Status}

Eight experiments have been performed since the start of the SPI initiative. Different samples, such as FIB Au nanostructures, rice dwarf virus (RDV), coliphage PR772 viruses and bacteriophage MS2 virus, were used for the various experiments. The reasons for the sample selection will be discussed in the sample selection section. The main purpose of each experiment was different. For example, amo86615 aimed primarily to collect a lot of diffraction patterns of RDV and PR772. However, the main target for experiment amo11416 was to test sample delivery and collect diffraction data from MS2. To reduce the background from sample delivery, different sample methods were tested.

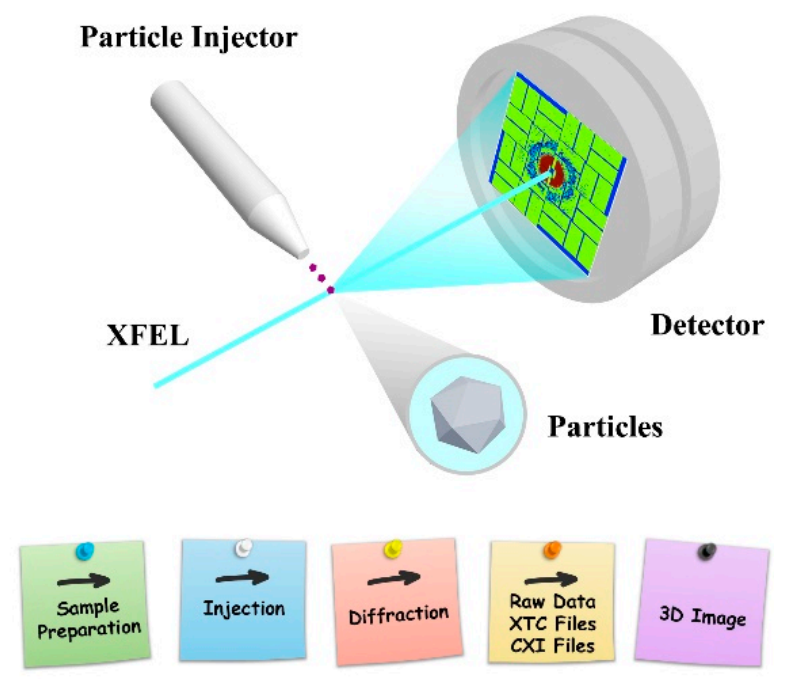

Figure 4. Schematic layout of a single-particle imaging measurement using femtosecond XFEL pulses. Nanoparticles and viruses are injected to the XFEL focus by a particle injector or a fixed target system using thin membranes such as $\mathrm{Si}_{3} \mathrm{~N}_{4}$ and graphene. High dynamic range, high quantum efficiency and large panel detectors are employed to record patterns. In general, five main steps are required for a single-particle imaging experiment. After sample selection and preparation, they are delivered to the XFEL focus and the patterns are collected by the detector. This produces large data sets requiring advanced automatic processing. Hit finding, background subtraction and detector calibrations have to be applied to reduce the data. By using threshold analysis or diffusion maps, single-shot patterns are selected. After orientation determination and phase retrieval, a real-space three-dimensional image can in principle be achieved.

\subsection{Light Source and Instruments}

There are seven X-ray instruments at the LCLS. The Coherent X-ray Imaging (CXI) instrument and the Atomic, Molecular \& Optical Science (AMO) instrument are the instruments suitable for SPI. The CXI instrument is located in the Far Experimental Hall of LCLS. The hutch is located $440 \mathrm{~m}$ far away from the source. The instrument makes use of hard X-ray pulses to perform coherent X-ray imaging and serial femtosecond crystallography experiments. The primary operating photon energy range is $5 \sim 11 \mathrm{keV}$, with some capability for higher harmonics up to $25 \mathrm{keV}$. Three sample chambers exist with foci of $\sim 5 \mu \mathrm{m}, 1 \mu \mathrm{m}$, and $0.1 \mu \mathrm{m}$ being possible. The AMO instrument is located in the Near Experimental Hall of LCLS and the photon energy range is $280 \sim 2000 \mathrm{eV}$. The focusing optics for the AMO instrument are bendable Kirkpatrick-Baez (KB) mirrors and the focused beam size is estimated to be $1.5 \sim 5 \mu \mathrm{m}$. In both the CXI and AMO cases, a high-power laser synchronized with the X-ray laser 
is available. Figure 5 shows a simple layout of AMO and CXI instruments. More detailed information can be found from reference [144-146] and from the LCLS facility website [147,148].

As mentioned in the setup and experiment procedure section, photon parameters should be determined before the experiment. The selection of the photon energy is very important to single particle imaging. As shown by momentum transfer $q=4 \pi \sin \theta / \lambda$ ( $2 \theta$ is the scattering angle), to obtain higher resolution, higher photon energy is needed. On the contrary, for higher photon energy, the wavelength is shorter and the coherent scattering cross-section is weaker. In order to estimate the scattering intensity per shot, a sphere model with uniform electron density can be used [149],

$$
I(q)=I_{0} r_{e}^{2} \Delta \Omega|\Delta \rho|^{2}\left(4 \pi \frac{\sin (R q)-R q \cos (R q)}{q^{3}}\right)^{2}
$$

where $I_{0}$ is the incident intensity, $r_{e}$ is the classical electron radius, $\Delta \rho$ is the difference of the complex electron density of the sphere to the medium and $R$ is the sphere radius. If we take the complex refractive index into the above equation, we can get the maximum ring intensity [150],

$$
I_{\max }(q)=I_{0} r_{e}^{2} \Delta \Omega|\Delta \rho|^{2} 16 \pi^{2} R^{2} q^{-4}
$$

The intensity for high $q$ will decrease rapidly. For the same sample size and scattering angle, shorter wavelength will contribute to higher resolution but lower intensity. Therefore, the optimized photon energy should be chosen depends on proposed resolution and sample types.

(a)



Overview of the AMO instrument layout

(b)



\section{Overview of the CXI instrument layout}

Figure 5. Overview of Atomic, Molecular \& Optical Science (AMO) and Coherent X-ray Imaging (CXI) instrument layout. Distances are indicated in meters from the interaction region (IR) for AMO, $1 \mu \mathrm{m}$ sample chamber (SC) and in parentheses from the $100 \mathrm{~nm}$ SC for CXI. The X-ray beam enters the hutch and passes through the diagnostics (D) and slits (S) and is then focused by KB mirrors. (a) An optical laser in-coupling (L-IN) is located $0.4 \mathrm{~m}$ upstream of the IR. Two pairs of pnCCD detectors are located in different positions downstream of the IR; (b) For the CXI instrument, each chamber is colored to match its designed KB mirrors. A timing tool (TT) is designed to obtain the fine time between X-ray laser and pump laser. (Figures were reproduced from Reference $[145,146]$ with permission from International Union of Crystallography/IUCr). 
Another principle for the photon energy selection is the optimized X-ray energy range for specified experiment instruments. For different X-ray instruments at LCLS or different beamlines at SACLA, the optimized photon energy varies. The commonly used photon energy for SPI is $1700 \mathrm{eV}$ that just below the Si K-edge at AMO, $7 \mathrm{keV}$ at CXI that below the Fe edge of $7.1 \mathrm{keV}, \mathrm{LCLS}$. Also, the photon count ability of detectors has also been considered during the photon energy selection. Other photon energies, such as $1250 \mathrm{eV}, 1800 \mathrm{eV}, 5 \mathrm{keV}$ and $10 \mathrm{keV}$ have also been used and tested, with varying degrees of success. A balance has to be struck between the resolution and scattering efficiency, and the ability for the various detectors to count photons with a reasonable signal to noise ratio.

High harmonics are an inevitable aspect of XFEL sources. Radiation at the fundamental wavelength dominates but appreciable levels of high harmonics also present at the $1 \%$ level. These harmonics may extend the capability of instruments but also may contribute background to experiments. The Soft X-ray Offset Mirror System (SOMS) and Hard X-ray Offset Mirror System (HOMS) located in the Front End Enclosure of LCLS have harmonic cutoffs at $\sim 2.5$ and $\sim 25 \mathrm{keV}$ respectively. The SOMS operate in the FEL energy range from $0.20 \mathrm{keV}$ to $2.0 \mathrm{keV}$ and the reflectivity is above $90 \%$ [151]. The system reflectivity above $2.48 \mathrm{keV}$ is below $20 \%$, which contributes to suppressing the third harmonic FEL peak [152]. The fundamental operation energy range for HOMS is $2.0 \sim 12.0 \mathrm{keV}$, and be able to deliver $2 \sim 25 \mathrm{keV}$ photons up to the third harmonic. From former measurement, it is known that the second harmonic content in normal operation at soft $\mathrm{X}$-ray region (near $1 \mathrm{keV}$ ) is $0.04 \sim 0.1 \%$, and the third harmonic is as high as $2.0 \sim 2.5 \%$ [153]. The third harmonic for hard X-ray wavelength $(6 \sim 8 \mathrm{keV})$ is $0.2 \sim 2 \%$. The reflectivity for the second and third harmonics are different for the downstream KB mirrors located at the experiment station, which provide some level of harmonic rejection. The third harmonic can produce undesired noise, for example via fluorescence by crossing above an absorption edge such as iron, a material making up most of the vacuum chamber. It is also less efficiently block by apertures and slits and can again increase the background noise.

Knowing and optimizing the focused beam size and the wavefront is another key aspect of SPI experiments [154]. The position and angles of KB mirrors should ideally be aligned for every SPI experiments. Imprint methods have been employed for the AMO and CXI instruments to find the best focusing position $[155,156]$. This is a time-consuming procedure for the current experiments. Two to three hours are usually required. According to the nature of SASE mode, the beam position and intensity fluctuates shot-to-shot. The SPI initiative has also taken the phenomenon into consideration. A backscattering position and intensity monitor was used for diagnostic for the CXI instruments [157].

The parasitic scattering of particle injectors is the primary source of scatter, the team is still working on this problem. Apart from particle injector scattering, the left stray scattering comes from the upstream components of the beamline. For the AMO instrument, the parasitic scattering comes from the roughness of KB mirrors. For the CXI instrument, the stray scattering comes from the diamond window that is located downstream of the $\mathrm{KB}$ mirrors to protect the mirrors from particles. The detailed information will come out soon by the SPI team. For SPI experiments, the alignment of apertures is also of great importance. $\mathrm{Ge}, \mathrm{Si}, \mathrm{Si}_{3} \mathrm{~N}_{4}$ and $\mathrm{B}_{4} \mathrm{C}$ apertures are typically used depending on the instrument and photon energy. Background levels from apertures of different materials have been investigated with varying performance depending on the material and thickness. For example, cleaved and etched Ge was found to be a good choice for hard X-rays around $7 \mathrm{keV}$.

The typical LCLS pulse energy for SPI is $2 \sim 5 \mathrm{~mJ}$, equals to $7.80 \times 10^{12} 1.95 \times 10^{13}$ photons/pulse@1.6 keV and 1.78 4.46 $\times 10^{12}$ photons/pulse@7.0 keV. The calculation of photon number per pulse was based on the $100 \%$ efficiency assumption of optical system. Actually, the efficiency is closer to $50 \%$. More photons typically mean higher SNR with stability being desirable. A single diffraction pattern is just one slice from the 3D diffraction volume. The number of photons interacting with the sample is different due to the intensity fluctuations shot-to-shot. The side effects of intensity fluctuations to the SPI 3D diffraction volume also need further study. Figure 6 shows the pulse intensity fluctuation with shots (time), the common fluctuation of intensity is $\sim 10 \%$. Also, the focused beam position fluctuates. The relative 
positions between $\mathrm{X}$-ray laser beam and the sample are also different shot to shot. This leads to different incident photons onto samples and means that for SPI, is not so easy to normalize every frame.

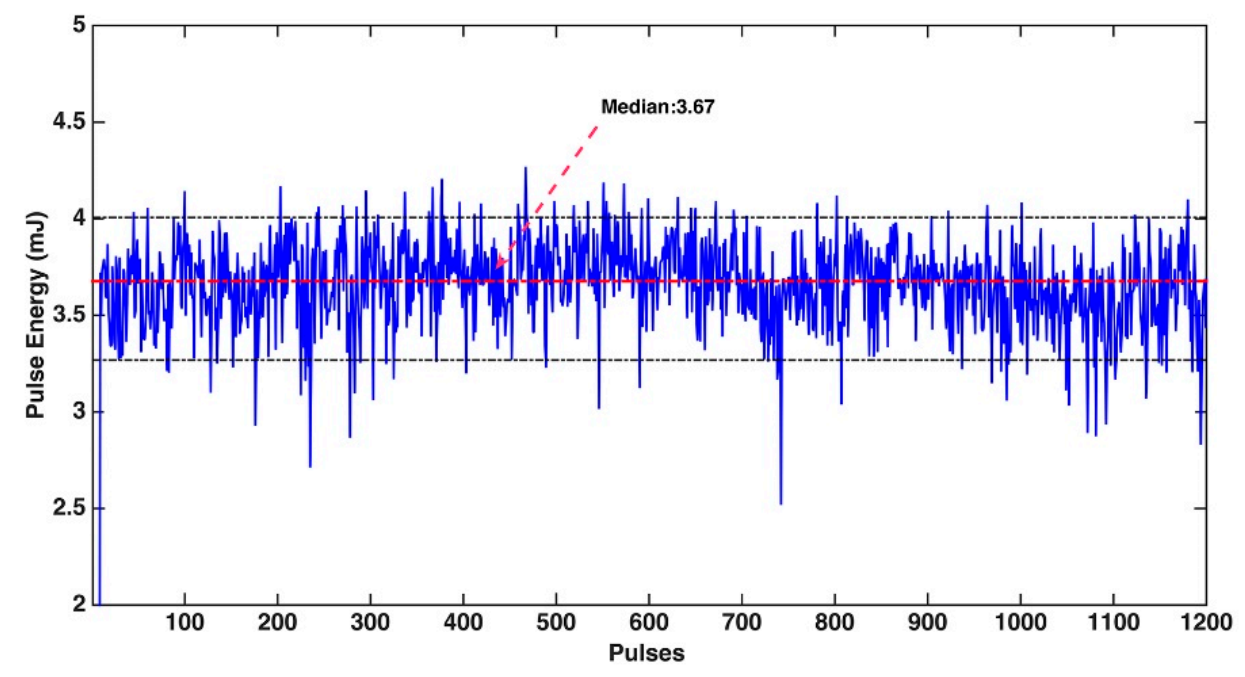

Figure 6. Pulse energy fluctuation with time. The intensity and position fluctuations come from the origin of SASE. The common fluctuations are typically $10 \%$ but sometimes as high as $30 \%$.

The pulse duration is another main factor for XFEL experiments. Short pulse duration is always required to outrun radiation damage. However, since shorter pulses usually come with a reduced number of photons, a balance is needed between pulse duration and pulse energy, a balance between damage and signal. For biological samples and molecules, Auger decay is predominant in carbon, nitrogen and oxygen [158]. The photoelectric effects will lead to a removal of two electrons from these elements. The energy and lifetime of these two electrons are different [159-161]. To figure out the exact Auger emission time scale and non-elastic scattering for specified samples is complex. However, the classic simulation and crystalline experiments have demonstrated that the radiation damage could be reduced or eliminated by using shorter pulses, such as $<10 \mathrm{fs}$ [100]. For SPI, to guarantee enough photons per pulse, the commonly used pulse duration is 30 70 fs. At the current limited resolution, these pulse durations do not lead to noticeable damage. For higher spatial resolution, radiation damage will be a limit for the development of SPI $[25,162,163]$.

\subsection{Sample Selection}

For the development phase of SPI, the selection of samples is key. To make things easier, choosing a high $\mathrm{Z}$ material is tempting, but this is not very representative of samples that are the ultimate goal of the method with the scattering strength of high $Z$ nanoparticles being stronger than bioparticles and biomolecules. Nevertheless, as initial steps towards developing aspects of the SPI methods, such artificial test samples can prove useful. Nanofabricated samples present the challenge of producing particles with regular shapes and sizes, a key requirement for putting together a consistent 3D diffraction volume from multiple copies of an object. This is also a challenge for bioparticles but less so.

The sample size should be smaller than the focused beam size. If the X-ray pulse only illuminates part of a single particle, one does not get a diffraction pattern representative of the whole object and therefore cannot merge this data reliably. As the sample quantities needed are large, the cost, mass production capacity should also be considered. High concentration should also be easy to achieve to improve the hit rate. Last but not least, the particles should be able to be aerosolized stably for injection to the XFEL beam. Under these principles, gold octahedra with size range from $2 \mu \mathrm{m}$ to $100 \mathrm{~nm}$ were produced by a polyol process [164]. For bioparticles, RDV, PR772 and MS2 were selected. RDV (Rice 
Dwarf Virus, Figure 7a) is an icosahedral RNA virus of about $70 \mathrm{~nm}$ in diameter [165]. A 3D structure of the capsid was determined by X-ray crystallography with a resolution of $3.5 \AA$. The associated PDB ID is 1UF2 [166]. PR772 (Figure 7b) is a lipid-containing bacteriophage that infects E. coli [167]. The diameter of this icosahedral virus is about $69 \mathrm{~nm}$. Unfortunately, the inner arrangement and structures of lipid layer and DNA are also not clearly known. MS2 (Figure 7c) is a bacteriophage that infects $\mathrm{F}+E$. coli. The diameter of this icosahedral virus is about $26 \mathrm{~nm}$ [168]. The internal arrangement of the complex is unknown.

(a)

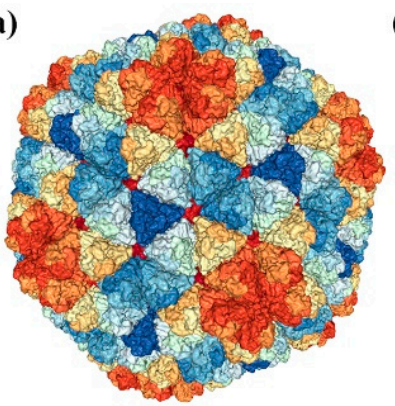

(b)



(c)



Figure 7. Projections of bioparticles used for SPI experiments. (a) Biological assembly of doubleshelled rice dwarf virus (RDV). RDV is a member of the genus Phytoreovirus in the family Reoviridae. The atomic structure was determined by X-ray crystallography at $3.5 \AA$ resolution [166]; (b) Quasi-atomic structure resolution model of bacteriophage PRD1 wild type virion. PR772 belongs to the PRD1 family. The dsDNA bacteriophage has a membrane inside its icosahedral capsid. The atomic structure was determined by combined cryo-EM and X-ray crystallography at $25 \AA$ resolution [169]; (c) Crystal structures of MS2 coat protein mutants in complex with wild-type RNA operator fragments. MS2 is a group I RNA bacteriophage that infects Escherichia coli. The atomic structure was resolved by X-ray crystallography at a resolution of $2.8 \AA$ [170]. The projections were generated by NSL Viewer, a WebGL based 3D viewer [171,172].

\subsection{Sample Delivery}

Sample delivery is a key component of XFEL experiments. There are two mainly used methods: (a) fix the sample by solid support, fixed target method; (b) Inject the particle streams into X-ray laser beam path, injection method. For the first method, $\mathrm{Si}_{3} \mathrm{~N}_{4}$ membrane or amorphous carbon film are regularly used. The method has been used for many 2D crystalline samples and synchrotron-based CDI experiments. However, the diffraction background is strong and can overwhelm the signal from the sample if $\mathrm{Si}_{3} \mathrm{~N}_{4}$ is used. For particle injectors, there are many injector devices commonly used by scientists. The gas dynamic virtual nozzle (GDVN) injector [173], delivers samples inside an unbroken liquid stream with tunable diameter by changing nozzle diameter and gas flow rate. The main general drawback of the GDVN is that they don't form droplets that are small enough. Also, non-volatile components in the buffer solution trend to stick to the particle of interest, which will make valid single particle shot more challenging. Another drawback of the GDVN is the high rate of sample consumption. This is not a problem when the sample is easy to achieve or synthesis. But this will be a big problem when the sample is valuable and hard to get. For SPI specifically, the liquid carrier medium scatters X-rays much more than the sample itself and makes it unsuitable for measuring single particle diffraction patterns of biological sampels. To solve this problem, the GDVN is always used combine with aerodynamic lens stack or electrospray during the SPI experiments.

Another mainly used injector device is the aerosol injector. The particles can be focused by gradient pressure in the aerodynamic lens stack. The sample delivery method of choice for SPI is typically to transport the purified samples into the buffer solution and then aerosolized with helium gas using a GDVN and then introduced to the X-ray laser beam path via an aerodynamic lens. The purified samples could also be aerosolized by a gas nebulizer, such as electrospray [174], and then injected 
by the aerodynamic lens stack [175]. These unfortunately typically lead to low hit rates. For CXI nanofocusing, the hit rate is just $\sim 1 \%$ or lower. The number of diffraction patterns needed for high resolution is large, requiring a lot of beamtime, beyond what is reasonably possible. This is an issue that will need to be resolved for SPI to become a broadly useful method. Another challenge for SPI is the scattering background from residual gas of aerosol injector. Different gases, such as $\mathrm{He}$ and $\mathrm{CO}_{2}$, have been tested and there are indications that the background level is now limited by the aerosol carrier gas.

\subsection{Detector and Data Analysis}

Detector systems are critical important to all scientific experiments and SPI is not an exception. The 2017 Chemistry Nobel Prize was awarded to Cryo-EM, a powerful technology for single-particle protein crystal structures determination [176]. The current resolution is around $3 \AA$, comparable with the X-ray crystallography [177]. About 20 years ago, the first 3D reconstruction at the sub-nanometer resolution of icosahedra virus was around $10 \AA$. Since then, thousands of structures have been determined by the Cryo-EM at a resolution from $30 \AA$ to $3 \AA$ [3]. A breakthrough was suddenly made around 2014. Great progress was made with the direct electron detectors and single particle analysis methods [178]. From that moment, Cryo-EM has attracted much attention from biologists and chemists. Compared with the Cryo-EM, there is a long way to go for SPI. The current 3D resolution of SPI is about $10 \mathrm{~nm}$. The CXI nanofocusing data showed a post-sample aperture [179] limited resolution close to $5.9 \AA$ [180]. Figure 8 shows the calculated photons number vs resolution (Q). The integrated single hit signal is higher than the background. A real-space image could not be obtained from this data due to the lack of enough hits. While the main limitation currently is hit rate, improved detectors with lower noise and easier identification of single scattered photons from the noise will be required to achieve higher resolution imaging. The SPI detector of the future will need to combine the best of dark current, detector panel size, gain, readout noise, dynamic range and quantum efficiency, with an increased readout speed. For LCLS, the maximum pulse repetition is $120 \mathrm{~Hz}$. At the increased repetition rates of the European-XFEL and LCLS-II, new detectors are needed. Millions or more diffraction patterns are needed to obtain a high-resolution image. At the current hit rates of about $1 \%$, higher repetition rate X-ray FELs will have a profound impact. The main characteristics of detectors used or planned for SPI related experiments at LCLS, LCLS-II, European-XFEL, SACLA and SwissFEL are listed in Table 1 for reference.



Figure 8. Radial average of signals using hard X-rays. Elevated photon counts from the sample are visible up to an angle commensurate with 5.9 A resolution, this being the resolution limit set by the angular acceptance of a post-sample aperture. (reproduced with permission from [180]. Copyright Springer Nature, 2016). 
Table 1. Main characteristics of detectors used for LCLS, LCLS-II, European-XFEL and SACLA.

\begin{tabular}{|c|c|c|c|c|c|c|}
\hline & AMO, LCLS & CXI, LCLS & TXI, LCLS-II & SPB/SFX, European-XFEL & BL 2, SACLA & SwissFEL \\
\hline Detector & pnCCD & CSPAD $^{b}$ & $\mathrm{ePi} \times 10 \mathrm{k}$ & AGIPD $^{d}$ & MPCCD & JUNGFRAU $^{\mathrm{f}}$ \\
\hline Pixel Size $\left(\mu \mathrm{m}^{2}\right)$ & $75 \times 75$ & $110 \times 110$ & $100 \times 100$ & $200 \times 200$ & $50 \times 50$ & $75 \times 75$ \\
\hline Single Photon Sensitivity & Yes & Yes & Yes & Yes & Yes $^{\mathrm{e}}$ & Yes \\
\hline Quantum Efficiency & >80\%@0.3 12 keV & 97\%@8 keV & 85\%@5 keV & >80\%@0.3 25 keV & 85\%@5.5keV & Up to $85 \% @ 1 \mathrm{keV}$ \\
\hline Dynamic Range & $10^{3} @ 2 \mathrm{keV}$ & $3.5 \times 10^{2} @ 8 \mathrm{keV}$ & $\sim 10^{4} @ 8 \mathrm{keV}$ & >104@12.5 keV & $1.2 \times 10^{3} @ 6 \mathrm{keV}$ & $>10^{4} @ 12$ keV \\
\hline Noise $\left(\mathrm{e}^{-}\right)$ & $20 / 2^{a}$ & 300 & 120 & 265 & 300 & 100 \\
\hline Frame Rate (kHz) & 0.12 & 0.12 & $0.48 / 2 \sim 4 / 10 \sim 20^{\mathrm{c}}$ & 4500 & 0.06 & $0.1 \sim 2.4$ \\
\hline
\end{tabular}


Data analysis is obviously key to the final results. As XFEL beamtime is rare and precious around the world, to optimize the experimental parameters before the formal experiment and data collection period is of great importance to guarantee the success and save beamtime. Simulations based on physical theories, actual light source and instrument specifications will be a great help. The SPB/SFX instrument of the European XFEL created a start-to-end simulation (S2Esim) software (European-XFEL, Hamburg, Germany) [189] to help researchers figure out the optimized parameters for SPI experiments based on European XFEL accelerator and undulator data bank. Recently, a powerful program was designed for SPI to demonstrate single particle imaging under ultra-shot X-ray pulses [190]. LCLS is planning to leverage these developments from the European XFEL. Other open sources, such as condor [191], provided by Uppsala University can simulate speckle patterns, reconstructed images and evaluated resolution that based on photon energy, focusing beam spot size, sample type and detector, etc. These will help researchers design and optimize their experiments.

The quantity of raw data of XFEL experiments makes it fall under the big data category. Raw data files contain electron and photon beams parameters on a shoit by shot basis, instrument settings and motor positions, diagnostics and DAQ information. How to extract useful information from the raw data efficiently is challenging. To provide a user-friendly solution, LCLS, European-XFEL and SACLA created their own DAQ systems [192]. At the LCLS, data analysis department developed psana module that a python-script interfaces could be used online (real-time) offline and parallelized over many machines [193]. This data analysis strategy makes SPI data analysis easier by using building blocks.

Online data monitoring is also an important part of SPI experiments. To give an instant feedback from the SPI data collection, a Python-based software named Hummgbird (Uppsala University, Uppsala, Sweden) [194] was developed. This gives the needed fast feedback for the particle injector and instruments alignment or optimization.

Offline analysis of such big data sets is challenging. The LCLS data analysis department developed psocake [195], a GUI program that makes SPI data analysis simple. The input of experiment name, run number and detector ID will make diffraction data visible. Different masks, different algorithms for hit finding and multiple types of pixel readout (gain corrected ADU, common mode corrected ADU, pedestal corrected ADU, raw ADU and photon counts) make diffraction patterns preliminary analysis (e.g., ADUs to photons, background subtraction, hit finding) powerful and effective.

Apart from the shot-to-shot intensity variation, non-linear detector response, stray scattering from optics and injectors, sample heterogeneity and conformations mentioned above, multiple particle hits are also a challenge factor for offline data analysis. Significant progress has been made in classification algorithms by using diffusion maps [196]. Experimental data contains only intensities with no phase information. Diffusion map algorithms provide mathematical links to a cloud of points via the Laplace-Beltrami operator. Each point on a diffusion map represents a diffraction pattern as shown on Figure 9 [197]. Single hit, multiple-particle hit, water diffraction, background and defects from the detector are captured in such mapping. Diffusion map approaches will fail in the limit of strong background and low SNR for small particles (e.g., MS2). For that situation, the classification can be conducted by hand. This is time-consuming and the precision will be non-reproducible for different operators. To solve this problem, automatic and supervised machine learning methods are being developed. The convolutional neural network is based on VGG16 net. For training, simulated data and experiments data are both used. Further study is still needed but this represents a promising future approach.

After classification, orientation determination and phase retrieval are needed. The commonly used methods are generative topographic mapping (GTM) [198], expectation maximization compression (EMC) [199,200], correlation maximization [201], manifold [202,203] and angular correlation methods [204]. The current method of choice for orientation determination is EMC. The EMC algorithm is implemented in Dragonfly [205], which is a powerful python-script program. Figure 10 shows a 3D diffraction volume after orientation determination and assembly [206]. The associated 3D real-space image is reconstructed by error-reduction (ER) method. Many other phase retrieval algorithms could 
be used, such as hybrid-input-output (HIO), Guided-hybrid-input-output (GHIO), relaxed averaged alternating reflections (RAAR) and difference map (DM).

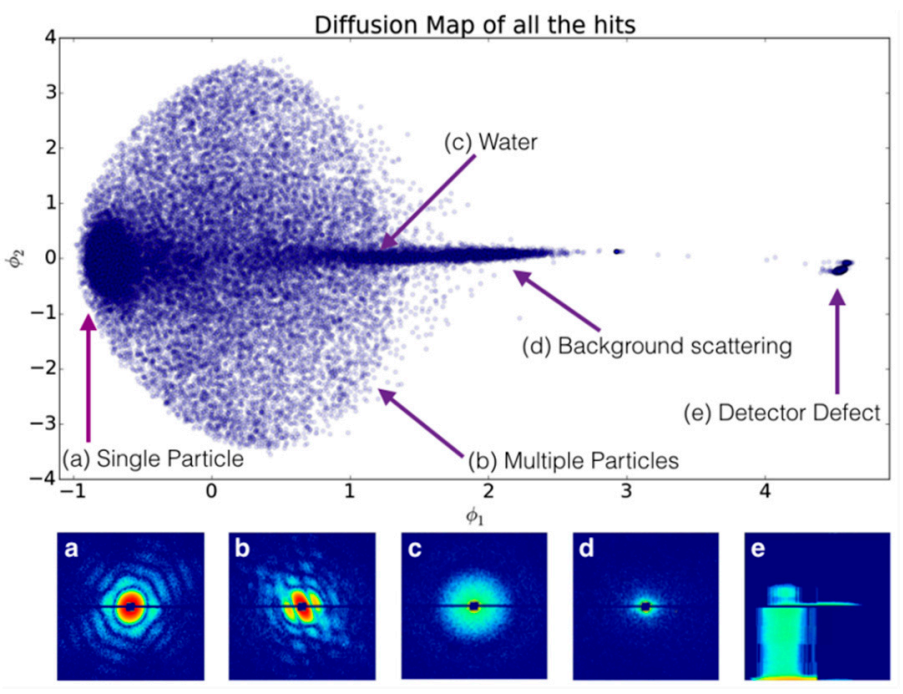

Figure 9. Diffusion map analysis of all hits. Large data sets were reduced to single-particle hit patterns. (a) Single-particle hit; (b) multiple-particle hit; (c) water diffraction that may contain contaminant residue from samples and buffer solutions; (d) background diffraction from detector; (e) detector defect pattern. (reproduced with permission from [197]. Copyright Springer Nature, 2017).
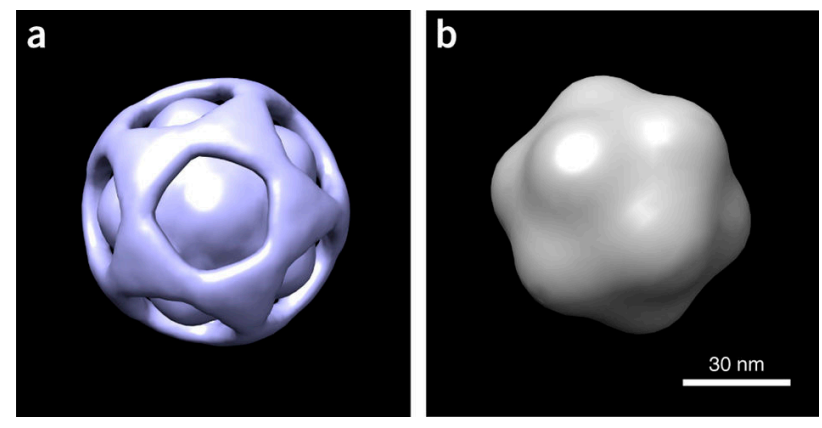

Figure 10. Three-dimensional diffraction pattern and reconstructed structure obtained without conformational analysis. (a) Diffraction pattern extracted from 37,550 2D single-particle diffraction snapshots of the PR772 virus, obtained at LCLS; (b) Corresponding 3D reconstructed image with a resolution of $9 \mathrm{~nm}$, corresponding to scattering to the edge of the detector. (reproduced with permission from [206]. Copyright Springer Nature, 2017).

Recently, great progress has been made in real-space image reconstruction phase retrieval algorithms, multi-tiered iterative phasing (M-TIP) [207]. M-TIP is an extension of standard iterative phasing algorithms, which recover the 3D internal intensity directly from fluctuation X-ray scattering data [208]. The angular cross-correlations method makes a valuable statistical tool for structural analysis. The approach in the case of scattering also offers a valuable opportunity for multi-particle analysis. Figure 11 shows the recovered 3D structures of RDV and PR772 by MTIP. A non-uniform distribution of internal structures was obtained.

\section{Summary and Future Prospects}

Since the start of the SPI initiative, eight experiments have been completed to try to overcome the technical challenges in achieving atomic resolution in single particles imaging with XFELs at the 
Linac Coherent Light Source. Two data papers have been published to describing experimental details and progress to date. Progress was also made by the SPI initiative members developing conformation change detection and new phase retrieval algorithm. The goals of past SPI experiments mainly focused on light source and instruments optimization, sample preparations and delivery development, background reduction and data analysis methods. The team achieved measurement signals at $\sim 6 \AA$ resolution, to the corner of the CSPAD detector used with the $100 \mathrm{~nm}$-focusing system of the CXI instrument. At the moment, the data is insufficient to reconstruct the 3D real-space image. On the other hand, hundreds of thousands of diffraction patterns were recorded by a far-field pnCCD at the AMO instrument using soft X-rays. Different team members have successfully reconstructed 3D real-space images using different methods at a full-period resolution of $\sim 10 \mathrm{~nm}$. Some of the SPI beamtime have been dedicated to the improvement of sample injection. Different injection methods, such as GDVN and electrospray for aerosolization, have been tested to reduce the background. This is still a challenge for further experiments. For the data analysis, classification has made rapid progress via the use of diffusion maps and machine learning. Powerful programs, such as psana, Condor, Hummingbird, Ondata, Dragonfly have made great contributions to SPI.



(d)



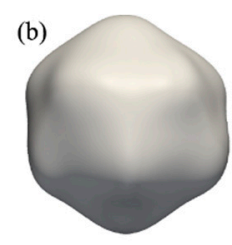

(e)



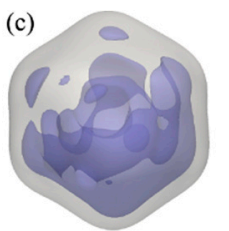

(f)

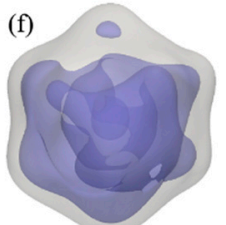

Figure 11. Three-dimensional reconstructed images of RDV (top row) and PR772 virus (bottom row). Two different views of the reconstructed RDV $(\mathbf{a}, \mathbf{b})$ and PR772 (d,e) particles, as well as density plots showing nonuniformities in the internal distribution of material inside the viruses $(\mathbf{c}, \mathbf{f})$. (reproduced with permission from [207]. Copyright American Physical Society, 2017).

For higher resolution in the near future, such as $5 \AA$ or better, more challenges lay ahead. The reproducibility of samples and homogeneity of internal structures are hard to guarantee. The hit rate and sample contaminations will have a great influence on the validity of patterns and numbers of valid frames. Higher resolution means more frames, this also requires more semi- and automatic data analysis methods. Not only are enough frames needed for 3D reconstructions but they also need enough photons in each frame for interpretation above noise. To totally outrun the radiation damage, the pulse duration should be reduced from 40 fs to below $10 \mathrm{fs}$ without too much loss in flux. High QE, high dynamic range and large array pixel area detector will also be a bottleneck for higher resolution approach using higher repetition rate machines. Fortunately, the European XFEL and LCLS-II are both developing such detectors.

A new tendency in scientific research is to share the data, sources and codes to the public [209-211]. With data sharing, the validity and repeatability of the analysis and interpretation can be tested by different institutes and personnel [212-216]. "Open science, data sharing, software sharing is the future of science", Carly Strasser says [209]. For SPI, this concept has also been accepted and will be extended to a wider range [217-220]. At the moment, most published data has been uploaded to the Coherent X-ray Imaging Data Bank (CXIDB) [221,222]. The community can download the raw data and try to reproduce the results. Commonly used tools can also be obtained easily from Github [223] or facility 
websites [224]. The move to make scientific findings transparent will speed up the challenging project and improve the scientific outcome.

Moving forward and overcoming the technical challenges can be painful, but this necessary method development effort is improving the prospects of single particle imaging with XFEL. High resolution $X$-ray based single particle imaging will make dynamic changes, light-induced phenomena, phase transition and femtosecond chemistry \& catalysis valuable possibility. This will provide a new horizon to the scientific community to explore the ultra-small and ultrafast world. The potential rewards are worth the effort and will only benefit from the advent of high repetition rate of state-of-the-art X-ray FELs such as the European-XFEL and LCLS-II.

Acknowledgments: We would like to thank the funding support from the National Natural Science Foundation of China (grant No. 31430031) and the Major State Basic Research Development Program of China (grant No. 2014CB910401). The Linac Coherent Light Source (LCLS) at the SLAC National Accelerator Laboratory is an Office of Science User Facility operated for the U.S. Department of Energy Office of Science by Stanford University. This work was: supported by the U.S. Department of Energy, Office of Science, Basic Energy Sciences under Contract No. DEAC02-76SF00515. We also would like to sincerely thank the stimulated discussions and help from Sébastien Boutet and Andrew L. Aquila at the Linac Coherent Light Source. Z.S. acknowledges funding from China Scholarship Council.

Author Contributions: Z.S. wrote the paper. All authors reviewed and critiqued the manuscript.

Conflicts of Interest: The authors declare no conflict of interest.

\section{References}

1. Opella, S.J. Structure Determination of Membrane Proteins by Nuclear Magnetic Resonance Spectroscopy. Annu. Rev. Anal. Chem. 2013, 6, 305-328. [CrossRef] [PubMed]

2. Garman, E.F. Developments in X-ray Crystallographic Structure Determination of Biological Macromolecules. Science 2014, 343, 1102-1108. [CrossRef] [PubMed]

3. Elmlund, D.; Elmlund, H. Cryogenic Electron Microscopy and Single-Particle Analysis. Annu. Rev. Biochem. 2015, 84, 499-517. [CrossRef] [PubMed]

4. Marsh, J.A.; Teichmann, S.A. Structure, Dynamics, Assembly, and Evolution of Protein Complexes. Annu. Rev. Biochem. 2015, 84, 551-575. [CrossRef] [PubMed]

5. Rajadhyaksha, M.; Grossman, M.; Esterowitz, D.; Webb, R.H.; Rox Anderson, R. In Vivo Confocal Scanning Laser Microscopy of Human Skin: Melanin Provides Strong Contrast. J. Investig. Dermatol. 1995, 104, $946-952$. [CrossRef] [PubMed]

6. Suzuki, T.; Fujikura, K.; Higashiyama, T.; Takata, K. DNA Staining for Fluorescence and Laser Confocal Microscopy. J. Histochem. Cytochem. 1997, 45, 49-53. [CrossRef] [PubMed]

7. Ntziachristos, V. Going deeper than microscopy: The optical imaging frontier in biology. Nat. Methods 2010, 7, 603-614. [CrossRef] [PubMed]

8. Willig, K.I.; Rizzoli, S.O.; Westphal, V.; Jahn, R.; Hell, S.W. STED microscopy reveals that synaptotagmin remains clustered after synaptic vesicle exocytosis. Nature 2006, 440, 935-939. [CrossRef] [PubMed]

9. Pawley, J.B. Fundamental Limits in Confocal Microscopy. In Handbook of Biological Confocal Microscopy; Springer: Boston, MA, USA, 2006; pp. 20-42, ISBN 978-03-8-745524-2.

10. Binnig, G.; Rohrer, H. Scanning tunneling microscopy. Surf. Sci. 1983, 126, 236-244. [CrossRef]

11. Binnig, G.; Quate, C.F.; Gerber, C. Atomic Force Microscope. Phys. Rev. Lett. 1986, 56, 930-933. [CrossRef] [PubMed]

12. Williams, D.B.; Carter, C.B. The Transmission Electron Microscope; Springer: Boston, MA, USA, 1996; ISBN 978-14-7-572519-3.

13. Reichelt, R. Scanning Electron Microscopy; Springer: New York, NY, USA, 2007; pp. 133-272. ISBN 978-03-8-749762-4.

14. Larson, B.C.; Yang, W.; Ice, G.E.; Budai, J.D.; Tischler, J.Z. Three-dimensional X-ray structural microscopy with submicrometre resolution. Nature 2002, 415, 887-890. [CrossRef] [PubMed]

15. Chao, W.; Harteneck, B.D.; Liddle, J.A.; Anderson, E.H.; Attwood, D.T. Soft X-ray microscopy at a spatial resolution better than $15 \mathrm{~nm}$. Nature 2005, 435, 1210-1213. [CrossRef] [PubMed]

16. Sakdinawat, A.; Attwood, D. Nanoscale X-ray imaging. Nat Photon. 2010, 4, 840-848. [CrossRef] 
17. Betzig, E.; Patterson, G.H.; Sougrat, R.; Lindwasser, O.W.; Olenych, S.; Bonifacino, J.S.; Davidson, M.W.; Lippincott-Schwartz, J.; Hess, H.F. Imaging Intracellular Fluorescent Proteins at Nanometer Resolution. Science 2006, 313, 1642-1645. [CrossRef] [PubMed]

18. Rust, M.J.; Bates, M.; Zhuang, X. Sub-diffraction-limit imaging by stochastic optical reconstruction microscopy (STORM). Nat. Methods 2006, 3, 793-796. [CrossRef] [PubMed]

19. Klar, T.A.; Jakobs, S.; Dyba, M.; Egner, A.; Hell, S.W. Fluorescence microscopy with diffraction resolution barrier broken by stimulated emission. Proc. Natl. Acad. Sci. USA 2000, 97, 8206-8210. [CrossRef] [PubMed]

20. Hofer, W.A.; Foster, A.S.; Shluger, A.L. Theories of scanning probe microscopes at the atomic scale. Rev. Mod. Phys. 2003, 75, 1287-1331. [CrossRef]

21. Kohl, L.R.H. Transmission Electron Microscopy, 5th ed.; Springer: New York, NY, USA, 2008; ISBN 978-03-8-740093-8.

22. Spence, J.C.H. High-Resolution Electron Microscopy, 4th ed.; Oxford University Press: New York, NY, USA, 2017; ISBN 978-01-9-879583-4.

23. Breedlove, J.R., Jr.; Trammell, G.T. Molecular Microscopy: Fundamental Limitations. Science 1970, 170, 1310-1313. [CrossRef] [PubMed]

24. Howells, M.R.; Beetz, T.; Chapman, H.N.; Cui, C.; Holton, J.M.; Jacobsen, C.J.; Kirz, J.; Lima, E.; Marchesini, S.; Miao, H.; et al. An assessment of the resolution limitation due to radiation-damage in X-ray diffraction microscopy. J. Electron. Spectrosc. Relat. Phenom. 2009, 170, 4-12. [CrossRef] [PubMed]

25. Barty, A.; Caleman, C.; Aquila, A.; Timneanu, N.; Lomb, L.; White, T.A.; Andreasson, J.; Arnlund, D.; Bajt, S.; Barends, T.R.M.; et al. Self-terminating diffraction gates femtosecond X-ray nanocrystallography measurements. Nat. Photon. 2012, 6, 35-40. [CrossRef] [PubMed]

26. Attwood, D. Soft X-rays and Extreme Ultraviolet Radiation: Principles and Applications, 1st ed.; Cambridge University Press: New York, NY, USA, 2007; ISBN 978-0521029971.

27. Mimura, H.; Handa, S.; Kimura, T.; Yumoto, H.; Yamakawa, D.; Yokoyama, H.; Matsuyama, S.; Inagaki, K.; Yamamura, K.; Sano, Y.; et al. Breaking the 10nm barrier in hard-X-ray focusing. Nat. Phys. 2010, 6, 122-125. [CrossRef]

28. Döring, F.; Robisch, A.L.; Eberl, C.; Osterhoff, M.; Ruhlandt, A.; Liese, T.; Schlenkrich, F.; Hoffmann, S.; Bartels, M.; Salditt, T.; et al. Sub-5 nm hard X-ray point focusing by a combined Kirkpatrick-Baez mirror and multilayer zone plate. Opt. Express 2013, 21, 19311-19323. [CrossRef] [PubMed]

29. Drenth, J. Principles of Protein X-ray Crystallography, 3rd ed.; Springer: New York, NY, USA, 2007; ISBN 978-0-387-33334-2.

30. Sayre, D. Some implications of a theorem due to Shannon. Acta. Crystallogr. 1952, 5, 843. [CrossRef]

31. Miao, J.; Sayre, D.; Chapman, H.N. Phase retrieval from the magnitude of the Fourier transforms of nonperiodic objects. J. Opt. Soc. Am. A 1998, 15, 1662-1669. [CrossRef]

32. Miao, J.; Ishikawa, T.; Anderson, E.H.; Hodgson, K.O. Phase retrieval of diffraction patterns from noncrystalline samples using the oversampling method. Phys. Rev. B 2003, 67, 174104. [CrossRef]

33. Fienup, J.R. Reconstruction of an object from modulus of Its Fourier-transform. Opt. Lett. 1978, 3, $27-29$. [CrossRef] [PubMed]

34. Fienup, J.R. Phase retrieval algorithms: A comparison. Appl. Opt. 1982, 21, 2758-2769. [CrossRef] [PubMed]

35. Fienup, J.R. Lensless coherent imaging by phase retrieval with an illumination pattern constraint. Opt. Express 2006, 14, 498-508. [CrossRef] [PubMed]

36. Bauschke, H.H.; Combettes, P.L.; Luke, D.R. Hybrid projection-reflection method for phase retrieval. J. Opt. Soc. Am. A 2003, 20, 1025-1034. [CrossRef]

37. Elser, V. Solution of the crystallographic phase problem by iterated projections. Acta Crystallogr. Sect. A Found. Crystallogr. 2003, 59, 201-209. [CrossRef]

38. Marchesini, S. X-ray image reconstruction from a diffraction pattern alone. Phys. Rev. B 2003, 68, 140101. [CrossRef]

39. Luke, D.R. Relaxed averaged alternating reflections for diffraction imaging. Inverse Probl. 2005, 21, 37-50. [CrossRef]

40. Chen, C.-C.; Miao, J.; Wang, C.W.; Lee, T.K. Application of optimization technique to noncrystalline x-ray diffraction microscopy: Guided hybrid input-output method. Phys. Rev. B 2007, 76, 064113. [CrossRef]

41. Marchesini, S. Invited Article: A unified evaluation of iterative projection algorithms for phase retrieval. Rev. Sci. Instrum. 2007, 78, 011301. [CrossRef] [PubMed] 
42. Miao, J.; Charalambous, P.; Kirz, J.; Sayre, D. Extending the methodology of X-ray crystallography to allow imaging of micrometre-sized non-crystalline specimens. Nature 1999, 400, 342-344. [CrossRef]

43. Robinson, I.K.; Vartanyants, I.A.; Williams, G.J.; Pfeifer, M.A.; Pitney, J.A. Reconstruction of the Shapes of Gold Nanocrystals Using Coherent X-Ray Diffraction. Phys. Rev. Lett. 2001, 87, 195505. [CrossRef] [PubMed]

44. Williams, G.J.; Pfeifer, M.A.; Vartanyants, I.A.; Robinson, I.K. Three-Dimensional Imaging of Microstructure in Au Nanocrystals. Phys. Rev. Lett. 2003, 90, 175501. [CrossRef] [PubMed]

45. Miao, J.; Chen, C.-C.; Song, C.; Nishino, Y.; Kohmura, Y.; Ishikawa, T.; Ramunno-Johnson, D.; Lee, T.-K.; Risbud, S.H. Three-dimensional GaN-Ga2O3 core shell structure revealed by x-ray diffraction microscopy. Phys. Rev. Lett. 2006, 97, 215503. [CrossRef] [PubMed]

46. Pfeifer, M.A.; Williams, G.J.; Vartanyants, I.A.; Harder, R.; Robinson, I.K. Three-dimensional mapping of a deformation field inside a nanocrystal. Nature 2006, 442, 63-66. [CrossRef] [PubMed]

47. Song, C.; Bergstrom, R.; Ramunno-Johnson, D.; Jiang, H.; Paterson, D.; de Jonge, M.D.; McNulty, I.; Lee, J.; Wang, K.L.; Miao, J. Nanoscale Imaging of Buried Structures with Elemental Specificity Using Resonant X-ray Diffraction Microscopy. Phys. Rev. Lett. 2008, 100, 025504. [CrossRef] [PubMed]

48. Robinson, I.; Harder, R. Coherent X-ray diffraction imaging of strain at the nanoscale. Nat. Mater. 2009, 8, 291-298. [CrossRef] [PubMed]

49. Jiang, H.; Ramunno-Johnson, D.; Song, C.; Amirbekian, B.; Kohmura, Y.; Nishino, Y.; Takahashi, Y.; Ishikawa, T.; Miao, J. Nanoscale imaging of mineral crystals inside biological composite materials using X-ray diffraction microscopy. Phys. Rev. Lett. 2008, 100, 038103. [CrossRef] [PubMed]

50. Jiang, H.; Xu, R.; Chen, C.-C.; Yang, W.; Fan, J.; Tao, X.; Song, C.; Kohmura, Y.; Xiao, T.; Wang, Y.; et al. Three-dimensional coherent $X$-ray diffraction imaging of molten iron in mantle olivine at nanoscale resolution. Phys. Rev. Lett. 2013, 110, 205501. [CrossRef] [PubMed]

51. Miao, J.; Hodgson, K.O.; Ishikawa, T.; Larabell, C.A.; LeGros, M.A.; Nishino, Y. Imaging whole Escherichia coli bacteria by using single-particle x-ray diffraction. Proc. Natl. Acad. Sci. USA 2003, 100, 110-112. [CrossRef] [PubMed]

52. Shapiro, D.; Thibault, P.; Beetz, T.; Elser, V.; Howells, M.; Jacobsen, C.; Kirz, J.; Lima, E.; Miao, H.; Neiman, A.M.; et al. Biological imaging by soft x-ray diffraction microscopy. Proc. Natl. Acad. Sci. USA 2005, 102, 15343-15346. [CrossRef] [PubMed]

53. Song, C.; Jiang, H.; Mancuso, A.; Amirbekian, B.; Peng, L.; Sun, R.; Shah, S.S.; Zhou, Z.H.; Ishikawa, T.; Miao, J. Quantitative imaging of single, unstained viruses with coherent X-rays. Phys. Rev. Lett. 2008, 101, 158101. [CrossRef] [PubMed]

54. Williams, G.J.; Hanssen, E.; Peele, A.G.; Pfeifer, M.A.; Clark, J.; Abbey, B.; Cadenazzi, G.; de Jonge, M.D.; Vogt, S.; Tilley, L.; et al. High-resolution X-ray imaging of Plasmodium falciparum-infected red blood cells. Cytom. Part A 2008, 73A, 949-957. [CrossRef] [PubMed]

55. Huang, X.; Nelson, J.; Kirz, J.; Lima, E.; Marchesini, S.; Miao, H.; Neiman, A.M.; Shapiro, D.; Steinbrener, J.; Stewart, A.; et al. Soft X-Ray Diffraction Microscopy of a Frozen Hydrated Yeast Cell. Phys. Rev. Lett. 2009, 103, 198101. [CrossRef] [PubMed]

56. Lima, E.; Wiegart, L.; Pernot, P.; Howells, M.; Timmins, J.; Zontone, F.; Madsen, A. Cryogenic X-Ray Diffraction Microscopy for Biological Samples. Phys. Rev. Lett. 2009, 103, 198102. [CrossRef] [PubMed]

57. Nishino, Y.; Takahashi, Y.; Imamoto, N.; Ishikawa, T.; Maeshima, K. Three-dimensional visualization of a human chromosome using coherent X-ray diffraction. Phys. Rev. Lett. 2009, 102, 018101. [CrossRef] [PubMed]

58. Nelson, J.; Huang, X.; Steinbrener, J.; Shapiro, D.; Kirz, J.; Marchesini, S.; Neiman, A.M.; Turner, J.J.; Jacobsen, C. High-resolution x-ray diffraction microscopy of specifically labeled yeast cells. Proc. Natl. Acad. Sci. USA 2010, 107, 7235-7239. [CrossRef] [PubMed]

59. Lima, E.; Diaz, A.; Guizar-Sicairos, M.; Gorelick, S.; Pernot, P.; Schleier, T.; Menzel, A. Cryo-scanning X-ray diffraction microscopy of frozen-hydrated yeast. J. Microsc. 2013, 249, 1-7. [CrossRef]

60. Nam, D.; Park, J.; Gallagher-Jones, M.; Kim, S.; Kim, S.; Kohmura, Y.; Naitow, H.; Kunishima, N.; Yoshida, T.; Ishikawa, T.; et al. Imaging fully hydrated whole cells by coherent $\mathrm{X}$-ray diffraction microscopy. Phys. Rev. Lett. 2013, 110, 098103. [CrossRef] [PubMed]

61. Song, C.; Takagi, M.; Park, J.; Xu, R.; Gallagher-Jones, M.; Imamoto, N.; Ishikawa, T. Analytic 3D Imaging of Mammalian Nucleus at Nanoscale Using Coherent X-rays and Optical Fluorescence Microscopy. Biophys. J. 2014, 107, 1074-1081. [CrossRef] [PubMed] 
62. Fan, J.; Sun, Z.; Zhang, J.; Huang, Q.; Yao, S.; Zong, Y.; Kohmura, Y.; Ishikawa, T.; Liu, H.; Jiang, H. Quantitative Imaging of Single Unstained Magnetotactic Bacteria by Coherent X-ray Diffraction Microscopy. Anal. Chem. 2015, 87, 5849-5853. [CrossRef] [PubMed]

63. Rodriguez, J.A.; Xu, R.; Chen, C.-C.; Huang, Z.; Jiang, H.; Chen, A.L.; Raines, K.S.; Pryor, A., Jr.; Nam, D.; Wiegart, L.; et al. Three-dimensional coherent X-ray diffractive imaging of whole frozen-hydrated cells. IUCrJ 2015, 2, 575-583. [CrossRef] [PubMed]

64. Williams, G.J.; Quiney, H.M.; Dhal, B.B.; Tran, C.Q.; Nugent, K.A.; Peele, A.G.; Paterson, D.; Jonge, M.D.D. Fresnel coherent diffractive imaging. Phys. Rev. Lett. 2006, 97, 025506. [CrossRef] [PubMed]

65. Abbey, B.; Nugent, K.A.; Williams, G.J.; Clark, J.N.; Peele, A.G.; Pfeifer, M.A.; de Jonge, M.; McNulty, I. Keyhole coherent diffractive imaging. Nat. Phys. 2008, 4, 394-398. [CrossRef]

66. Marathe, S.; Kim, S.S.; Kim, S.N.; Kim, C.; Kang, H.C.; Nickles, P.V.; Noh, D.Y. Coherent diffraction surface imaging in reflection geometry. Opt. Express 2010, 18, 7253-7262. [CrossRef] [PubMed]

67. Rodenburg, J.M.; Hurst, A.C.; Cullis, A.G.; Dobson, B.R.; Pfeiffer, F.; Bunk, O.; David, C.; Jefimovs, K.; Johnson, I. Hard-X-ray lensless imaging of extended objects. Phys. Rev. Lett. 2007, 98, 034801. [CrossRef] [PubMed]

68. Dierolf, M.; Menzel, A.; Thibault, P.; Schneider, P.; Kewish, C.M.; Wepf, R.; Bunk, O.; Pfeiffer, F. Ptychographic X-ray computed tomography at the nanoscale. Nature 2010, 467, 436-439. [CrossRef] [PubMed]

69. Miao, J.; Hodgson, K.O.; Sayre, D. An approach to three-dimensional structures of biomolecules by using single-molecule diffraction images. Proc. Natl. Acad. Sci. USA 2001, 98, 6641-6645. [CrossRef] [PubMed]

70. Miao, J.; Ishikawa, T.; Johnson, B.; Anderson, E.H.; Lai, B.; Hodgson, K.O. High Resolution 3D X-ray Diffraction Microscopy. Phys. Rev. Lett. 2002, 89, 088303. [CrossRef] [PubMed]

71. Nugent, K.A.; Peele, A.G.; Chapman, H.N.; Mancuso, A.P. Unique phase recovery for nonperiodic objects. Phys. Rev. Lett. 2003, 91, 203902. [CrossRef] [PubMed]

72. Chapman, H.N.; Barty, A.; Marchesini, S.; Noy, A.; Hau-Riege, S.P.; Cui, C.; Howells, M.R.; Rosen, R.; He, H.; Spence, J.C.H.; et al. High-resolution ab initio three-dimensional x-ray diffraction microscopy. J. Opt. Soc. Am. A 2006, 23, 1179-1200. [CrossRef]

73. Quiney, H.M.; Peele, A.G.; Cai, Z.; Paterson, D.; Nugent, K.A. Diffractive imaging of highly focused X-ray fields. Nat. Phys. 2006, 2, 101-104. [CrossRef]

74. Thibault, P.; Dierolf, M.; Menzel, A.; Bunk, O.; David, C.; Pfeiffer, F. High-Resolution Scanning X-ray Diffraction Microscopy. Science 2008, 321, 379-382. [CrossRef] [PubMed]

75. Chapman, H.N.; Nugent, K.A. Coherent lensless X-ray imaging. Nat. Photon. 2010, 4, 833-839. [CrossRef]

76. Giewekemeyera, K.; Thibaultb, P.; Kalbfleischa, S.; Beerlinka, A.; Kewishc, C.M.; Dierolfb, M.; Pfeifferb, F.; Salditta, T. Quantitative biological imaging by ptychographic X-ray diffraction microscopy. Proc. Natl. Acad. Sci. USA 2010, 107, 529-534. [CrossRef] [PubMed]

77. Jiang, H.; Song, C.; Chen, C.-C.; Xu, R.; Raines, K.S.; Fahimian, B.P.; Lu, C.-H.; Lee, T.-K.; Nakashima, A.; Urano, J.; et al. Quantitative 3D imaging of whole, unstained cells by using X-ray diffraction microscopy. Proc. Natl. Acad. Sci. USA 2010, 107, 11234-11239. [CrossRef] [PubMed]

78. Raines, K.S.; Salha, S.; Sandberg, R.L.; Jiang, H.; Rodriguez, J.A.; Fahimian, B.P.; Kapteyn, H.C.; Du, J.; Miao, J. Three-dimensional structure determination from a single view. Nature 2010, 463, 214-217. [CrossRef] [PubMed]

79. Abbey, B.; Whitehead, L.W.; Quiney, H.M.; Vine, D.J.; Cadenazzi, G.A.; Henderson, C.A.; Nugent, K.A.; Balaur, E.; Putkunz, C.T.; Peele, A.G.; et al. Lensless imaging using broadband X-ray sources. Nat. Photon. 2011, 5, 420-424. [CrossRef]

80. Roy, S.; Parks, D.; Seu, K.A.; Su, R.; Turner, J.J.; Chao, W.; Anderson, E.H.; Cabrini, S.; Kevan, S.D. Lensless X-ray imaging in reflection geometry. Nat. Photon. 2011, 5, 243-245. [CrossRef]

81. Tripathi, A.; Mohanty, J.; Dietze, S.H.; Shpyrko, O.G.; Shipton, E.; Fullerton, E.E.; Kim, S.S.; McNulty, I. Dichroic coherent diffractive imaging. Proc. Natl. Acad. Sci. USA 2011, 108, 13393-13398. [CrossRef] [PubMed]

82. Clark, J.N.; Huang, X.; Harder, R.; Robinson, I.K. High-resolution three-dimensional partially coherent diffraction imaging. Nat. Commun. 2012, 3, 993. [CrossRef] [PubMed]

83. Miao, J.; Sandberg, R.L.; Song, C. Coherent X-ray Diffraction Imaging. IEEE J. Sel. Top. Quantum Electron. 2012, 18, 399-410. [CrossRef]

84. Sun, T.; Jiang, Z.; Strzalka, J.; Ocola, L.; Wang, J. Three-dimensional coherent X-ray surface scattering imaging near total external reflection. Nat. Photon. 2012, 6, 586-590. [CrossRef] 
85. Szameit, A.; Shechtman, Y.; Osherovich, E.; Bullkich, E.; Sidorenko, P.; Dana, H.; Steiner, S.; Kley, E.B.; Gazit, S.; Cohen-Hyams, T.; et al. Sparsity-based single-shot subwavelength coherent diffractive imaging. Nat. Mater. 2012, 11, 455-459. [CrossRef] [PubMed]

86. Seaberg, M.D.; Zhang, B.; Gardner, D.F.; Shanblatt, E.R.; Murnane, M.M.; Kapteyn, H.C.; Adams, D.E. Tabletop nanometer extreme ultraviolet imaging in an extended reflection mode using coherent Fresnel ptychography. Optica 2014, 1, 39-44. [CrossRef]

87. Miao, J.; Ishikawa, T.; Robinson, I.K.; Murnane, M.M. Beyond crystallography: Diffractive imaging using coherent X-ray light sources. Science 2015, 348, 530-535. [CrossRef] [PubMed]

88. Chen, B.; Yusuf, M.; Hashimoto, T.; Estandarte, A.K.; Thompson, G.; Robinson, I. Three-dimensional positioning and structure of chromosomes in a human prophase nucleus. Sci. Adv. 2017, 3. [CrossRef] [PubMed]

89. HTML5 Word Cloud. Available online: https://github.com/timdream/wordcloud (accessed on 15 October 2017).

90. Eriksson, M.; van der Veen, J.F.; Quitmann, C. Diffraction-limited storage rings-A window to the science of tomorrow. J. Synchrotron Radiat. 2014, 21, 837-842. [CrossRef] [PubMed]

91. Hitchcock, A.P.; Toney, M.F. Spectromicroscopy and coherent diffraction imaging: Focus on energy materials applications. J. Synchrotron Radiat. 2014, 21, 1019-1030. [CrossRef] [PubMed]

92. Thibault, P.; Guizar-Sicairos, M.; Menzel, A. Coherent imaging at the diffraction limit. J. Synchrotron Radiat. 2014, 21, 1011-1018. [CrossRef] [PubMed]

93. Hettel, R. DLSR design and plans: An international overview. J. Synchrotron Radiat. 2014, 21, 843-855. [CrossRef] [PubMed]

94. Susini, J.; Barrett, R.; Chavanne, J.; Fajardo, P.; Gotz, A.; Revol, J.-L.; Zhang, L. New challenges in beamline instrumentation for the ESRF Upgrade Programme Phase II. J. Synchrotron Radiat. 2014, 21, 986-995. [CrossRef] [PubMed]

95. Tanaka, H.; Ishikawa, T. SPring-8 upgrade project. In Proceedings of the IPAC2016, Busan, Korea, 8-13 May 2016.

96. Tavares, P.F.; Leemann, S.C.; Sjostrom, M.; Andersson, A. The MAX IV storage ring project. J. Synchrotron Radiat. 2014, 21, 862-877. [CrossRef] [PubMed]

97. Liu, L.; Milas, N.; Mukai, A.H.C.; Resende, X.R.; de Sa, F.H. The Sirius project. J. Synchrotron Radiat. 2014, 21, 904-911. [CrossRef] [PubMed]

98. Madey, J.M.J. Stimulated Emission of Bremsstrahlung in a Periodic Magnetic Field. J. Appl. Phys. 1971, 42, 1906-1913. [CrossRef]

99. McNeil, B.W.J.; Thompson, N.R. X-ray free-electron lasers. Nat. Photon. 2010, 4, 814-821. [CrossRef]

100. Neutze, R.; Wouts, R.; Spoel, D.; Weckert, E.; Hajdu, J. Potential for biomolecular imaging with femtosecond X-ray pulses. Nature 2000, 406, 752-757. [CrossRef] [PubMed]

101. Chapman, H.N.; Barty, A.; Bogan, M.J.; Boutet, S.; Frank, M.; Hau-Riege, S.P.; Marchesini, S.; Woods, B.W.; Bajt, S.; Benner, W.H.; et al. Femtosecond diffractive imaging with a soft-X-ray free-electron laser. Nat. Phys. 2006, 2, 839-843. [CrossRef]

102. Chapman, H.N. Femtosecond X-ray protein nanocrystallography. Nature 2011, 470, 73-77. [CrossRef] [PubMed]

103. Aquila, A. The linac coherent light source single particle imaging road map. Struct. Dyn. 2015, 2, 041701. [CrossRef] [PubMed]

104. Tiedtke, K.; Azima, A.; Bargen, N.V.; Bittner, L.; Bonfigt, S.; Düsterer, S.; Faatz, B.; Frühling, U.; Gensch, M.; Gerth, C.; et al. The soft X-ray free-electron laser FLASH at DESY: Beamlines, diagnostics and end-stations. New J. Phys. 2009, 11, 023029. [CrossRef]

105. Free-Electron Laser FLASH. Available online: https:/ / flash.desy.de (accessed on 15 October 2017).

106. Emma, P.; Akre, R.; Arthur, J.; Bionta, R.; Bostedt, C.; Bozek, J.; Brachmann, A.; Bucksbaum, P.; Coffee, R.; Decker, F.J.; et al. First lasing and operation of an angstrom-wavelength free-electron laser. Nat. Photon. 2010, 4, 641-647. [CrossRef]

107. Linac Coherent Light Source. Available online: https:/ /cls.slac.stanford.edu (accessed on 15 December 2017).

108. Ishikawa, T.; Aoyagi, H.; Asaka, T.; Asano, Y.; Azumi, N.; Bizen, T.; Ego, H.; Fukami, K.; Fukui, T.; Furukawa, Y.; et al. A compact X-ray free-electron laser emitting in the sub-angstrom region. Nat. Photon. 2012, 6, 540-544. [CrossRef]

109. SACLA XFEL. Available online: http:/ /xfel.riken.jp/eng/ (accessed on 15 October 2017). 
110. Allaria, E.; Appio, R.; Badano, L.; Barletta, W.A.; Bassanese, S.; Biedron, S.G.; Borga, A.; Busetto, E.; Castronovo, D.; Cinquegrana, P.; et al. Highly coherent and stable pulses from the FERMI seeded free-electron laser in the extreme ultraviolet. Nat. Photon. 2012, 6, 699-704. [CrossRef]

111. Elettra and FERMI Lightsources. Available online: https://www.elettra.trieste.it/lightsources/fermi.html (accessed on 15 October 2017).

112. European XFEL. Available online: https:/ / www.xfel.eu (accessed on 15 October 2017).

113. Pohang Accelerator Laboratory. Available online: http://pal.postech.ac.kr/paleng/ (accessed on 15 October 2017).

114. SwissFEL. Available online: https://www.psi.ch/swissfel/ (accessed on 15 October 2017).

115. Wang, D. Soft X-ray Free-electron Laser at SINAP. In Proceedings of the IPAC2016, Busan, Korea, 8-13 May 2016.

116. Zhao, Z.; Wang, D.; Gu, Q.; Yin, L.; Gu, M.; Leng, Y.; Liu, B. Status of the SXFEL Facility. Appl. Sci. 2017, 7, 607. [CrossRef]

117. Zhu, Z.; Zhao, Z.; Wang, D.; Liu, Z.; Li, R.; Yin, L.; Yang, Z.H. SCLF: An 8-GeV CW SCRF linac-based X-ray FEL facility in Shanghai. In Proceedings of the FEL2017, Santa Fe, NM, USA, 20-25 August 2017.

118. Gaffney, K.J.; Chapman, H.N. Imaging atomic structure and dynamics with ultrafast X-ray scattering. Science 2007, 316, 1444-1448. [CrossRef] [PubMed]

119. Vartanyants, I.A.; Robinson, I.K.; McNulty, I.; David, C.; Wochner, P.; Tschentscher, T. Coherent X-ray scattering and lensless imaging at the European XFEL Facility. J. Synchrotron Radiat. 2007, 14, 453-470. [CrossRef] [PubMed]

120. Barty, A.; Boutet, S.; Bogan, M.J.; Hau-Riege, S.; Marchesini, S.; Sokolowski-Tinten, K.; Stojanovic, N.; Tobey, R.A.; Ehrke, H.; Cavalleri, A.; et al. Ultrafast single-shot diffraction imaging of nanoscale dynamics. Nat. Photon. 2008, 2, 415-419. [CrossRef]

121. Bogan, M.J.; Benner, W.H.; Boutet, S.; Rohner, U.; Frank, M.; Barty, A.; Seibert, M.M.; Maia, F.; Marchesini, S.; Bajt, S.; et al. Single particle X-ray diffractive imaging. Nano Lett. 2008, 8, 310-316. [CrossRef] [PubMed]

122. Mancuso, A.P.; Schropp, A.; Reime, B.; Stadler, L.-M.; Singer, A.; Gulden, J.; Streit-Nierobisch, S.; Gutt, C.; Bel, G.G.; Feldhaus, J.; et al. Coherent-pulse 2D crystallography using a free-electron laser X-ray source. Phys. Rev. Lett. 2009, 102, 035502. [CrossRef] [PubMed]

123. Bogan, M.J.; Boutet, S.; Chapman, H.N.; Marchesini, S.; Barty, A.; Benner, W.H.; Rohner, U.; Frank, M.; Hau-Riege, S.P.; Bajt, S.; et al. Aerosol Imaging with a Soft X-Ray Free Electron Laser. Aerosol Sci. Technol. 2010, 44, i-vi. [CrossRef]

124. Hau-Riege, S.P.; Boutet, S.; Barty, A.; Bajt, S.; Bogan, M.J.; Frank, M.; Andreasson, J.; Iwan, B.; Seibert, M.M.; Hajdu, J.; et al. Sacrificial Tamper Slows Down Sample Explosion in FLASH Diffraction Experiments. Phys. Rev. Lett. 2010, 104, 064801. [CrossRef] [PubMed]

125. Kassemeyer, S.; Steinbrener, J.; Lomb, L.; Hartmann, E.; Aquila, A.; Barty, A.; Martin, A.V.; Hampton, C.Y.; Bajt, S.; Barthelmess, M.; et al. Femtosecond free-electron laser x-ray diffraction data sets for algorithm development. Opt. Express 2012, 20, 4149-4158. [CrossRef] [PubMed]

126. Loh, N.D.; Hampton, C.Y.; Martin, A.V.; Starodub, D.; Sierra, R.G.; Barty, A.; Aquila, A.; Schulz, J.; Lomb, L.; Steinbrener, J.; et al. Fractal morphology, imaging and mass spectrometry of single aerosol particles in flight. Nature 2012, 486, 513-517. [CrossRef] [PubMed]

127. Starodub, D.; Aquila, A.; Bajt, S.; Barthelmess, M.; Barty, A.; Bostedt, C.; Bozek, J.D.; Coppola, N.; Doak, R.B.; Epp, S.W.; et al. Single-particle structure determination by correlations of snapshot X-ray diffraction patterns. Nat. Commun. 2012, 3, 1276. [CrossRef] [PubMed]

128. Clark, J.N.; Beitra, L.; Xiong, G.; Higginbotham, A.; Fritz, D.M.; Lemke, H.T.; Zhu, D.; Chollet, M.; Williams, G.J.; Messerschmidt, M.; et al. Ultrafast Three-Dimensional Imaging of Lattice Dynamics in Individual Gold Nanocrystals. Science 2013, 341, 56-59. [CrossRef] [PubMed]

129. Takahashi, Y.; Suzuki, A.; Zettsu, N.; Oroguchi, T.; Takayama, Y.; Sekiguchi, Y.; Kobayashi, A.; Yamamoto, M.; Nakasako, M. Coherent Diffraction Imaging Analysis of Shape-Controlled Nanoparticles with Focused Hard X-ray Free-Electron Laser Pulses. Nano Lett. 2013, 13, 6028-6032. [CrossRef] [PubMed]

130. Andreasson, J.; Martin, A.V.; Liang, M.; Timneanu, N.; Aquila, A.; Wang, F.; Iwan, B.; Svenda, M.; Ekeberg, T.; Hantke, M.; et al. Automated identification and classification of single particle serial femtosecond X-ray diffraction data. Opt. Express 2014, 22, 2497-2510. [CrossRef] [PubMed]

131. Xu, R.; Jiang, H.; Song, C.; Rodriguez, J.A.; Huang, Z.; Chen, C.-C.; Nam, D.; Park, J.; Gallagher-Jones, M.; Kim, S.; et al. Single-shot three-dimensional structure determination of nanocrystals with femtosecond X-ray free-electron laser pulses. Nat. Commun. 2014, 5, 4061. [CrossRef] [PubMed] 
132. Clark, J.N.; Beitra, L.; Xiong, G.; Fritz, D.M.; Lemke, H.T.; Zhu, D.; Chollet, M.; Williams, G.J.; Messerschmidt, M.M.; Abbey, B.; et al. Imaging transient melting of a nanocrystal using an X-ray laser. Proc. Natl. Acad. Sci. USA 2015, 112, 7444-7448. [CrossRef] [PubMed]

133. Mancuso, A.P.; Gorniak, T.; Staier, F.; Yefanov, O.M.; Barth, R.; Christophis, C.; Reime, B.; Gulden, J.; Singer, A.; Pettit, M.E.; et al. Coherent imaging of biological samples with femtosecond pulses at the free-electron laser FLASH. New J. Phys. 2010, 12, 035003. [CrossRef]

134. Seibert, M.M.; Boutet, S.; Svenda, M.; Ekeberg, T.; Maia, F.R.N.C.; Bogan, M.J.; Tîmneanu, N.; Barty, A.; Hau-Riege, S.; Caleman, C.; et al. Femtosecond diffractive imaging of biological cells. J. Phys. B At. Mol. Opt. Phys. 2010, 43, 194015. [CrossRef]

135. Seibert, M.M.; Ekeberg, T.; Maia, F.R.N.C.; Svenda, M.; Andreasson, J.; Jonsson, O.; Odic, D.; Iwan, B.; Rocker, A.; Westphal, D.; et al. Single mimivirus particles intercepted and imaged with an X-ray laser. Nature 2011, 470, 78-81. [CrossRef] [PubMed]

136. Gallagher-Jones, M.; Bessho, Y.; Kim, S.; Park, J.; Kim, S.; Nam, D.; Kim, C.; Kim, Y.; Noh, D.Y.; Miyashita, O.; et al. Macromolecular structures probed by combining single-shot free-electron laser diffraction with synchrotron coherent X-ray imaging. Nat. Commun. 2014, 5, 3798. [CrossRef] [PubMed]

137. Hantke, M.F.; Hasse, D.; Maia, F.R.N.C.; Ekeberg, T.; John, K.; Svenda, M.; Loh, N.D.; Martin, A.V.; Timneanu, N.; Larsson, D.S.D.; et al. High-throughput imaging of heterogeneous cell organelles with an X-ray laser. Nat. Photon. 2014, 8, 943-949. [CrossRef]

138. Kimura, T.; Joti, Y.; Shibuya, A.; Song, C.; Kim, S.; Tono, K.; Yabashi, M.; Tamakoshi, M.; Moriya, T.; Oshima, T.; et al. Imaging live cell in micro-liquid enclosure by X-ray laser diffraction. Nat. Commun. 2014, 5, 3052. [CrossRef] [PubMed]

139. Ekeberg, T.; Svenda, M.; Abergel, C.; Maia, F.R.N.C.; Seltzer, V.; Claverie, J.-M.; Hantke, M.; Jönsson, O.; Nettelblad, C.; Van Der Schot, G. Three-dimensional reconstruction of the giant mimivirus particle with an x-ray free-electron laser. Phys. Rev. Lett. 2015, 114, 098102. [CrossRef] [PubMed]

140. Takayama, Y.; Inui, Y.; Sekiguchi, Y.; Kobayashi, A.; Oroguchi, T.; Yamamoto, M.; Matsunaga, S.; Nakasako, M. Coherent $X$-Ray Diffraction Imaging of Chloroplasts from Cyanidioschyzon merolae by Using X-Ray Free Electron Laser. Plant Cell Physiol. 2015, 56, 1272-1286. [CrossRef] [PubMed]

141. Schot, G.V.D.; Svenda, M.; Maia, F.R.N.C.; Hantke, M.; DePonte, D.P.; Seibert, M.M.; Aquila, A.; Schulz, J.; Kirian, R.; Liang, M.; et al. Imaging single cells in a beam of live cyanobacteria with an X-ray laser. Nat. Commun. 2015, 6, 5704. [CrossRef] [PubMed]

142. Fan, J.; Sun, Z.; Wang, Y.; Park, J.; Kim, S.; Gallagher-Jones, M.; Kim, Y.; Song, C.; Yao, S.; Zhang, J.; et al. Single-pulse enhanced coherent diffraction imaging of bacteria with an X-ray free-electron laser. Sci. Rep. 2016, 6, 34008. [CrossRef] [PubMed]

143. Bostedt, C.; Thomas, H.; Hoener, M.; Eremina, E.; Fennel, T.; Meiwes-Broer, K.H.; Wabnitz, H.; Kuhlmann, M.; Plönjes, E.; Tiedtke, K.; et al. Multistep Ionization of Argon Clusters in Intense Femtosecond Extreme Ultraviolet Pulses. Phys. Rev. Lett. 2008, 100, 133401. [CrossRef] [PubMed]

144. Sébastien, B.; Garth, J.W. The Coherent X-ray Imaging (CXI) instrument at the Linac Coherent Light Source (LCLS). New J. Phys. 2010, 12, 035024. [CrossRef]

145. Ferguson, K.R.; Bucher, M.; Bozek, J.D.; Carron, S.; Castagna, J.-C.; Coffee, R.; Curiel, G.I.; Holmes, M.; Krzywinski, J.; Messerschmidt, M.; et al. The Atomic, Molecular and Optical Science instrument at the Linac Coherent Light Source. J. Synchrotron Radiat. 2015, 22, 492-497. [CrossRef] [PubMed]

146. Liang, M.; Williams, G.J.; Messerschmidt, M.; Seibert, M.M.; Montanez, P.A.; Hayes, M.; Milathianaki, D.; Aquila, A.; Hunter, M.S.; Koglin, J.E.; et al. The Coherent X-ray Imaging instrument at the Linac Coherent Light Source. J. Synchrotron Radiat. 2015, 22, 514-519. [CrossRef] [PubMed]

147. Coherent X-ray Imaging (CXI). Available online: https://lcls.slac.stanford.edu/instruments/cxi (accessed on 15 December 2017).

148. Atomic, Molecular \& Optical Science (AMO). Available online: https:/ /cls.slac.stanford.edu/instruments / amo (accessed on 15 December 2017).

149. Starodub, D.; Rez, P.; Hembree, G.; Howells, M.; Shapiro, D.; Chapman, H.N.; Fromme, P.; Schmidt, K.; Weierstall, U.; Doak, R.B.; et al. Dose, exposure time and resolution in serial X-ray crystallography. J. Synchrotron Radiat. 2008, 15, 62-73. [CrossRef] [PubMed]

150. Spence, J.C.H. X-ray Lasers in Biology: Structure and Dynamics. Adv. Imag. Electron Phys. 2017, 200, $103-152$. [CrossRef] 
151. Pivovaroffa, M.J.; Biontaa, R.M.; Mccarvillea, T.J.; Souflia, R.; Stefanb, P.M. Soft X-ray Mirrors for the Linac Coherent Light Source. Proc. SPIE 2007, 6705, 670500. [CrossRef]

152. Soufli, R.; Pivovaroff, M.J.; Baker, S.L.; Robinson, J.C.; Gullikson, E.M.; McCarville, T.J.; Stefan, P.M.; Aquila, A.L.; Ayers, J.; McKernan, M.A.; et al. Development, characterization and experimental performance of X-ray optics for the LCLS free-electron laser. Proc. SPIE 2008, 7077, 707716. [CrossRef]

153. Ratner, D.; Brachmann, A.; Decker, F.J.; Ding, Y.; Dowell, D.; Emma, P.; Fisher, A.; Frisch, J.; Gilevich, S.; Huang, Z.; et al. Second and third harmonic measurements at the linac coherent light source. Phys. Rev. ST Accel. Beams 2011, 14, 060701. [CrossRef]

154. Barty, A.; Soufli, R.; McCarville, T.; Baker, S.L.; Pivovaroff, M.J.; Stefan, P.; Bionta, R. Predicting the coherent X-ray wavefront focal properties at the Linac Coherent Light Source (LCLS) X-ray free electron laser. Opt. Express 2009, 17, 15508-15519. [CrossRef] [PubMed]

155. Hau-Riege, S.P.; Pardini, T. The effect of electron transport on the characterization of X-ray free-electron laser pulses via ablation. Appl. Phys. Lett. 2017, 111, 144102. [CrossRef]

156. David, C.; Gorelick, S.; Rutishauser, S.; Krzywinski, J.; Vila-Comamala, J.; Guzenko, V.A.; Bunk, O.; Färm, E.; Ritala, M.; Cammarata, M.; et al. Nanofocusing of hard X-ray free electron laser pulses using diamond based Fresnel zone plates. Sci. Rep. 2011, 1. [CrossRef] [PubMed]

157. Feng, Y.; Feldkamp, J.M.; Fritz, D.M.; Cammarata, M.; Robert, A.; Caronna, C.; Lemke, H.T.; Zhu, D.; Lee, S.; Boutet, S.; et al. A single-shot intensity-position monitor for hard X-ray FEL sources. Proc. SPIE 2011, 8140, 81400Q. [CrossRef]

158. Hau-Riege, S.P.; London, R.A.; Szoke, A. Dynamics of biological molecules irradiated by short x-ray pulses. Phys. Rev. B 2004, 69, 051906. [CrossRef] [PubMed]

159. Ziaja, B.; van der Spoel, D.; Szöke, A.; Hajdu, J. Auger-electron cascades in diamond and amorphous carbon. Phys. Rev. B 2001, 64, 214104. [CrossRef]

160. Ziaja, B.; de Castro, A.R.B.; Weckert, E.; Möller, T. Modelling dynamics of samples exposed to free-electron-laser radiation with Boltzmann equations. Eur. Phys. J. D 2006, 40, 465-480. [CrossRef]

161. Caleman, C.; Ortiz, C.; Marklund, E.; Bultmark, F.; Gabrysch, M.; Parak, F.G.; Hajdu, J.; Klintenberg, M.; Tîmneanu, N. Radiation damage in biological material: Electronic properties and electron impact ionization in urea. EPL 2009, 88, 29901. [CrossRef]

162. Young, L.; Kanter, E.P.; Krässig, B.; Li, Y.; March, A.M.; Pratt, S.T.; Santra, R.; Southworth, S.H.; Rohringer, N.; DiMauro, L.F.; et al. Femtosecond electronic response of atoms to ultra-intense X-rays. Nature 2010, 466, 56-61. [CrossRef] [PubMed]

163. Garman, E.F.; Weik, M. Radiation damage to biological macromolecules: Some answers and more questions. J. Synchrotron Radiat. 2013, 20, 1-6. [CrossRef] [PubMed]

164. Yuan, L.; Yang, M.; Qu, F.; Shen, G.; Yu, R. Seed-mediated growth of platinum nanoparticles on carbon nanotubes for the fabrication of electrochemical biosensors. Electrochim. Acta 2008, 53, 3559-3565. [CrossRef]

165. Zhong, B.; Kikuchi, A.; Moriyasu, Y.; Higashi, T.; Hagiwara, K.; Omura, T. A minor outer capsid protein, P9, of Rice dwarf virus. Arch. Virol. 2003, 148, 2275-2280. [CrossRef] [PubMed]

166. Nakagawa, A.; Miyazaki, N.; Taka, J.; Naitow, H.; Ogawa, A.; Fujimoto, Z.; Mizuno, H.; Higashi, T.; Watanabe, Y.; Omura, T.; et al. The Atomic Structure of Rice dwarf Virus Reveals the Self-Assembly Mechanism of Component Proteins. Structure 2003, 11, 1227-1238. [CrossRef] [PubMed]

167. Coetzee, J.N.; Lecatsas, G.; Coetzee, W.F.; Hedges, R.W. Properties of R plasmid R772 and the corresponding pilus-specific phage PR772. J. Gen. Microbiol. 1979, 110, 263-273. [CrossRef] [PubMed]

168. Toropova, K.; Basnak, G.; Twarock, R.; Stockley, P.G.; Ranson, N.A. The Three-dimensional Structure of Genomic RNA in Bacteriophage MS2: Implications for Assembly. J. Mol. Biol. 2008, 375, 824-836. [CrossRef] [PubMed]

169. Martín, C.S.; Burnett, R.M.; de Haas, F.; Heinkel, R.; Rutten, T.; Fuller, S.D.; Butcher, S.J.; Bamford, D.H. Combined EM/X-Ray Imaging Yields a Quasi-Atomic Model of the Adenovirus-Related Bacteriophage PRD1 and Shows Key Capsid and Membrane Interactions. Structure 2001, 9, 917-930. [CrossRef]

170. Worm, S.H.E.V.D.; Stonehouse, N.J.; Valegård, K.; Murray, J.B.; Walton, C.; Fridborg, K.; Stockley, P.G.; Liljas, L. Crystal structures of MS2 coat protein mutants in complex with wild-type RNA operator fragments. Nucleic Acids Res. 1998, 26, 1345-1351. [CrossRef] [PubMed] 
171. Rose, A.S.; Bradley, A.R.; Valasatava, Y.; Duarte, J.M.; Prlić, A.; Rose, P.W. Web-based molecular graphics for large complexes. In Proceedings of the 21st International Conference on Web3D Technology, Anaheim, CA, USA, 22-24 July 2016; pp. 185-186.

172. Rose, A.S.; Hildebrand, P.W. NGL Viewer: A web application for molecular visualization. Nucleic Acids Res. 2015, 43, W576-W579. [CrossRef] [PubMed]

173. DePonte, D.P. Gas dynamic virtual nozzle for generation of microscopic droplet streams. J. Phys. D Appl Phys. 2008, 41, 195505. [CrossRef]

174. Sierra, R.G. Nanoflow electrospinning serial femtosecond crystallography. Acta Cryst. D 2012, 68, $1584-1587$. [CrossRef] [PubMed]

175. Kirian, R.A.; Awel, S.; Eckerskorn, N.; Fleckenstein, H.; Wiedorn, M.; Adriano, L.; Bajt, S.; Barthelmess, M.; Bean, R.; Beyerlein, K.R.; et al. Simple convergent-nozzle aerosol injector for single-particle diffractive imaging with X-ray free-electron lasers. Struct. Dyn. 2015, 2, 041717. [CrossRef] [PubMed]

176. The Nobel Prize in Chemistry 2017. Available online: https:/ / www.nobelprize.org/nobel_prizes/chemistry/ laureates /2017/ (accessed on 15 October 2017).

177. Fernandez-Leiro, R.; Scheres, S.H.W. Unravelling biological macromolecules with cryo-electron microscopy. Nature 2016, 537, 339-346. [CrossRef] [PubMed]

178. Cheng, Y. Single-particle cryo-EM at crystallographic resolution. Cell 2015, 161, 450-457. [CrossRef] [PubMed]

179. Wiedorn, M.O.; Awel, S.; Morgan, A.J.; Barthelmess, M.; Bean, R.; Beyerlein, K.R.; Chavas, L.M.G.; Eckerskorn, N.; Fleckenstein, H.; Heymann, M.; et al. Post-sample aperture for low background diffraction experiments at X-ray free-electron lasers. J. Synchrotron Radiat. 2017, 24, 1296-1298. [CrossRef] [PubMed]

180. Munke, A.; Andreasson, J.; Aquila, A.; Awel, S.; Ayyer, K.; Barty, A.; Bean, R.J.; Berntsen, P.; Bielecki, J.; Boutet, S.; et al. Coherent diffraction of single Rice Dwarf virus particles using hard X-rays at the Linac Coherent Light Source. Sci. Data 2016, 3, 160064. [CrossRef] [PubMed]

181. Strüder, L.; Epp, S.; Rolles, D.; Hartmann, R.; Holl, P.; Lutz, G.; Soltau, H.; Eckart, R.; Reich, C.; Heinzinger, K.; et al. Large-format, high-speed, X-ray pnCCDs combined with electron and ion imaging spectrometers in a multipurpose chamber for experiments at 4 th generation light sources. Nucl. Instrum. Methods Phys. Res. A 2010, 614, 483-496. [CrossRef]

182. Blaj, G.; Caragiulo, P.; Carini, G.; Carron, S.; Dragone, A.; Freytag, D.; Haller, G.; Hart, P.; Hasi, J.; Herbst, R.; et al. X-ray detectors at the Linac Coherent Light Source. J. Synchrotron Radiat. 2015, 22, 577-583. [CrossRef] [PubMed]

183. Blaj, G.; Caragiulo, P.; Carini, G.; Dragone, A.; Haller, G.; Hart, P.; Hasi, J.; Herbst, R.; Kenney, C.; Markovic, B.; et al. Future of ePix detectors for high repetition rate FELs. AIP Conf. Proc. 2016, 1741, 040012. [CrossRef]

184. Blaj, G.; Caragiulo, P.; Carini, G.; Carron, S.; Dragone, A.; Freytag, D.; Haller, G.; Hart, P.; Herbst, R.; Herrmann, S.; et al. Detector Development for the Linac Coherent Light Source. Synchrotron Radiat. News 2014, 27, 14-19. [CrossRef]

185. Greiffenberg, D. The AGIPD detector for the European XFEL. J. Instrum. 2012, 7, C01103. [CrossRef]

186. Allahgholi, A.; Becker, J.; Bianco, L.; Delfs, A.; Dinapoli, R.; Goettlicher, P.; Graafsma, H.; Greiffenberg, D.; Hirsemann, H.; Jack, S.; et al. AGIPD, a high dynamic range fast detector for the European XFEL. J. Instrum. 2015, 10, C01023. [CrossRef]

187. Kameshima, T.; Ono, S.; Kudo, T.; Ozaki, K.; Kirihara, Y.; Kobayashi, K.; Inubushi, Y.; Yabashi, M.; Horigome, T.; Holland, A.; et al. Development of an X-ray pixel detector with multi-port charge-coupled device for X-ray free-electron laser experiments. Rev. Sci. Instrum. 2014, 85, 033110. [CrossRef] [PubMed]

188. Jungmann-Smith, J.H.; Bergamaschi, A.; Bruckner, M.; Cartier, S.; Dinapoli, R.; Greiffenberg, D.; Huthwelker, T.; Maliakal, D.; Mayilyan, D.; Medjoubi, K.; et al. Towards hybrid pixel detectors for energy-dispersive or soft X-ray photon science. J. Synchrotron Radiat. 2016, 23, 385-394. [CrossRef] [PubMed]

189. Yoon, C.H.; Yurkov, M.V.; Schneidmiller, E.A.; Samoylova, L.; Buzmakov, A.; Jurek, Z.; Ziaja, B.; Santra, R.; Loh, N.D.; Tschentscher, T.; et al. A comprehensive simulation framework for imaging single particles and biomolecules at the European X-ray Free-Electron Laser. Sci. Rep. 2016, 6, 24791. [CrossRef] [PubMed]

190. Fortmann-Grote, C.; Buzmakov, A.; Jurek, Z.; Loh, N.-T.D.; Samoylova, L.; Santra, R.; Schneidmiller, E.A.; Tschentscher, T.; Yakubov, S.; Yoon, C.H.; et al. Start-to-end simulation of single-particle imaging using ultra-short pulses at the European X-ray Free-Electron Laser. IUCrJ 2017, 4, 560-568. [CrossRef] [PubMed] 
191. Hantke, M.F.; Ekeberg, T.; Maia, F.R.N.C. Condor: A simulation tool for flash X-ray imaging. J. Appl. Cryst. 2016, 49, 1356-1362. [CrossRef] [PubMed]

192. Thayer, J.; Damiani, D.; Ford, C.; Gaponenko, I.; Kroeger, W.; O'Grady, C.; Pines, J.; Tookey, T.; Weaver, M.; Perazzo, A. Data systems for the Linac Coherent Light Source. J. Appl. Cryst. 2016, 49, 1363-1369. [CrossRef]

193. Damiani, D. Linac Coherent Light Source data analysis using psana. J. Appl. Cryst. 2016, 49, $672-679$. [CrossRef]

194. Daurer, B.J.; Hantke, M.F.; Nettelblad, C.; Maia, F.R.N.C. Hummingbird: Monitoring and analyzing flash X-ray imaging experiments in real time. J. Appl. Cryst. 2016, 49, 1042-1047. [CrossRef] [PubMed]

195. Psocake SPI Tutorial. Available online: https:/ / confluence.slac.stanford.edu/display/PSDM/Psocake+SPI+ tutorial (accessed on 15 October 2017).

196. Coifman, R.R.; Lafon, S. Diffusion maps. Appl. Comput. Harmon. Anal. 2006, 21, 5-30. [CrossRef]

197. Reddy, H.K.N.; Yoon, C.H.; Aquila, A.; Awel, S.; Ayyer, K.; Barty, A.; Berntsen, P.; Bielecki, J.; Bobkov, S.; Bucher, M.; et al. Coherent soft X-ray diffraction imaging of coliphage PR772 at the Linac coherent light source. Sci. Data 2017. [CrossRef] [PubMed]

198. Fung, R.; Shneerson, V.; Saldin, D.K.; Ourmazd, A. Structure from fleeting illumination of faint spinning objects in flight. Nat. Phys. 2008, 5, 64. [CrossRef]

199. Loh, N.D.; Bogan, M.J.; Elser, V.; Barty, A.; Boutet, S.; Bajt, S.; Hajdu, J.; Ekeberg, T.; Maia, F.R.N.C.; Schulz, J.; et al. Cryptotomography: Reconstructing 3D Fourier Intensities from Randomly Oriented Single-Shot Diffraction Patterns. Phys. Rev. Lett. 2010, 104, 225501. [CrossRef] [PubMed]

200. Moths, B.; Ourmazd, A. Bayesian algorithms for recovering structure from single-particle diffraction snapshots of unknown orientation: A comparison. Acta Cryst. A 2011, 67, 481-486. [CrossRef] [PubMed]

201. Tegze, M.; Bortel, G. Atomic structure of a single large biomolecule from diffraction patterns of random orientations. J. Struct. Biol. 2012, 179, 41-45. [CrossRef] [PubMed]

202. Giannakis, D.; Schwander, P.; Ourmazd, A. The symmetries of image formation by scattering. I. Theoretical framework. Opt. Express 2012, 20, 12799-12826. [CrossRef] [PubMed]

203. Schwander, P.; Giannakis, D.; Yoon, C.H.; Ourmazd, A. The symmetries of image formation by scattering. II. Applications. Opt. Express 2012, 20, 12827-12849. [CrossRef] [PubMed]

204. Saldin, D.K.; Poon, H.C.; Schwander, P.; Uddin, M.; Schmidt, M. Reconstructing an icosahedral virus from single-particle diffraction experiments. Opt. Express 2011, 19, 17318-17335. [CrossRef] [PubMed]

205. Ayyer, K.; Lan, T.-Y.; Elser, V.; Loh, N.D. Dragonfly: An implementation of the expand-maximize-compress algorithm for single-particle imaging. J. Appl. Cryst. 2016, 49, 1320-1335. [CrossRef] [PubMed]

206. Hosseinizadeh, A.; Mashayekhi, G.; Copperman, J.; Schwander, P.; Dashti, A.; Sepehr, R.; Fung, R.; Schmidt, M.; Yoon, C.H.; Hogue, B.G.; et al. Conformational landscape of a virus by single-particle X-ray scattering. Nat. Methods 2017, 14, 877-881. [CrossRef] [PubMed]

207. Kurta, R.P.; Donatelli, J.J.; Yoon, C.H.; Berntsen, P.; Bielecki, J.; Daurer, B.J.; DeMirci, H.; Fromme, P.; Hantke, M.F.; Maia, F.R.N.C.; et al. Correlations in Scattered X-Ray Laser Pulses Reveal Nanoscale Structural Features of Viruses. Phys. Rev. Lett. 2017, 119, 158102. [CrossRef] [PubMed]

208. Donatelli, J.J.; Zwart, P.H.; Sethian, J.A. Iterative phasing for fluctuation X-ray scattering. Proc. Natl. Acad. Sci. USA 2015, 112, 10286-10291. [CrossRef] [PubMed]

209. Gewin, V. Data sharing: An open mind on open data. Nature 2016, 529, 117-119. [CrossRef] [PubMed]

210. Ince, D.C.; Hatton, L.; Graham-Cumming, J. The case for open computer programs. Nature 2012, 482, 485-488. [CrossRef] [PubMed]

211. Anonymous. Announcement: Transparency upgrade for Nature journals. Nature 2017, 543, 288. [CrossRef]

212. Baker, M. Independent labs to verify high-profile papers. Nature 2012. [CrossRef]

213. Anonymous. Announcement: Reducing our irreproducibility. Nature 2013, 496, 398. [CrossRef]

214. McNutt, M. Reproducibility. Science 2014, 343, 229. [CrossRef] [PubMed]

215. Allison, D.B.; Brown, A.W.; George, B.J.; Kaiser, K.A. Reproducibility: A tragedy of errors. Nature 2016, 530, 27-29. [CrossRef] [PubMed]

216. Loeb, A. Good data are not enough. Nature 2016, 539, 23-25. [CrossRef] [PubMed]

217. Daurer, B.J.; Okamoto, K.; Bielecki, J.; Maia, F.R.N.C.; Muhlig, K.; Seibert, M.M.; Hantke, M.F.; Nettelblad, C.; Benner, W.H.; Svenda, M.; et al. Experimental strategies for imaging bioparticles with femtosecond hard X-ray pulses. IUCrJ 2017, 4, 251-262. [CrossRef] [PubMed] 
218. Ekeberg, T.; Svenda, M.; Seibert, M.M.; Abergel, C.; Maia, F.R.N.C.; Seltzer, V.; DePonte, D.P.; Aquila, A.; Andreasson, J.; Iwan, B.; et al. Single-shot diffraction data from the Mimivirus particle using an X-ray free-electron laser. Sci. Data 2016, 3, 160060. [CrossRef] [PubMed]

219. Hantke, M.F.; Hasse, D.; Ekeberg, T.; John, K.; Svenda, M.; Loh, D.; Martin, A.V.; Timneanu, N.; Larsson, D.S.D.; van der Schot, G.; et al. A data set from flash X-ray imaging of carboxysomes. Sci. Data 2016, 3, 160061. [CrossRef] [PubMed]

220. Van der Schot, G.; Svenda, M.; Maia, F.R.N.C.; Hantke, M.F.; DePonte, D.P.; Seibert, M.M.; Aquila, A.; Schulz, J.; Kirian, R.A.; Liang, M.; et al. Open data set of live cyanobacterial cells imaged using an X-ray laser. Sci. Data 2016, 3, 160058. [CrossRef] [PubMed]

221. Maia, F.R.N.C. The Coherent X-ray Imaging Data Bank. Nat. Methods 2012, 9, 854-855. [CrossRef] [PubMed]

222. Coherent X-Ray Imaging Data Bank (CXIDB). Available online: http://www.cxidb.org (accessed on 15 October 2017).

223. Dragonfly. Available online: https://github.com/duaneloh/Dragonfly/wiki (accessed on 15 October 2017).

224. Condor (Online Tool for CXI Pattern Simulation). Available online: http://1mb.icm.uu.se/condor/ simulation/ (accessed on 15 October 2017).

(C) 2018 by the authors. Licensee MDPI, Basel, Switzerland. This article is an open access article distributed under the terms and conditions of the Creative Commons Attribution (CC BY) license (http://creativecommons.org/licenses/by/4.0/). 